\title{
The Role of Ambidexterity in Marketing Strategy Implementation: Resolving the Exploration-Exploitation Dilemma
}

\author{
Christiane Prange, EM Lyon Business School, France, E-Mail: prange@em-lyon.com \\ Bodo B. Schlegelmilch, WU Wien, Austria, and Leeds University Business School, UK, E-Mail: bodo.schlegelmilch@wu-wien.ac.at
}

\begin{abstract}
Formulating consistent marketing strategies is a difficult task, but successfully implementing them is even more challenging. This is even more pertinent as marketing strategies quite often incorporate inherent conflicts between major breakthroughs and consolidation. Consequently, marketers need to balance exploratory and exploitative strategies. However, the literature lacks concrete insights for marketing managers as to how exploratory and exploitative strategies can be best combined. This paper addresses this issue by introducing a framework of multiple types of ambidexterity. Based on qualitative research, tools and procedures are identified to overcome marketing dilemmas and support strategy implementation by drawing on ambidextrous designs.
\end{abstract}

Keywords: marketing dilemmas, marketing strategy implementation, exploration, exploitation, ambidexterity

Manuscript received November 19, 2008, accepted by Adamantios Diamantopoulos (Marketing), November 11, 2009.

\section{$1 \quad$ Introduction}

Marketers are faced with a dilemma: they are expected to consolidate their existing business while simultaneously finding new opportunities. They are torn between exploitation and exploration, or between alignment and innovation. Thus, implementing the right strategy is often difficult. Business development may be eager to sell new products that have not yet completed the research process. $R \& D$ may develop new product ideas, but fail to commercialize them (Souder and Chakrabarti 1978; Griffin and Hauser 1996). Firms are market-driven while market-driving firms are more conducive to innovations (Kumar 1997; Jaworski, Kohli, and Sahay 2000). And as if these tensions were not enough, marketing managers are also challenged to act locally but integrate globally, and to pursue differentiation but obverse low-cost strategies (Ghoshal and Bartlett 1994; Porter 1996; Tushman and O'Reilly 1996).
Despite the growing interest among researchers and the pressing need of practitioners, there is a dearth of research that investigates the implementation of conflicting marketing strategies. The handful of existing studies to date has broadly focused on the marketing strategy formulation-implementation link (Bonoma 1984; Crespedes 1991; Walker and Rueckert 1987; White, Conand, and Echambadi 2003) with only tangential reference to theoretically derived implementation guidelines. Consequently, the literature suffers from several limitations. First, previous research has either focused on isolated factors in support of strategy implementation or has highlighted rather complex frameworks (Li, Guohui, and Eppler 2008) with holistic studies using simple categorizations of various factors without theoretical integration (Noble and Mokwa 1999). Second, research has largely overlooked the various roles of managers and employees in the strategy implementation process (Hart and Banbury 1994). This lack of an organization-wide perspective is noteworthy 
given the importance of functional interactions for implementation success (Chimhanzi and Morgan 2005). Finally, the majority of implementation studies has acknowledged that the changing content of strategy holds few clear implications and has consequently emphasized the necessity for managers to continuously redefine tasks and communicate them throughout the organization (Shashittal and Wilemon 1996). Notwithstanding the quest for ongoing adaptability of both strategy formulation and implementation processes, studies that focus on intrinsic tradeoffs in marketing strategies are rare.

These limitations present the starting point for our research and can be best illustrated with reference to the more content-oriented marketing literature where tradeoffs abound. For instance, customer satisfaction has become one of the unquestioned linchpins to success in marketing (e.g. Gale 1992) and it has been suggested to combine service activities with increasing sales efforts. However, doing so simultaneously is often problematic as customer service staff feels uncomfortable with the twin role of selling products while serving the customer (Akşin and Harker 1999; Evans, Arnold, and Grant 1999). While requests have been formulated to integrate internal structures, processes, goals and rewards to properly support the desired role behavior of customer contact personnel (Schneider and Bowen 1995), fine-grained insight on how this could be done is lacking.

A related dilemma is the tension in new product development: Incremental product improvements typically arise from small changes where return are certain, risks are low, and where products exhibit little deviation from customers' current experience. However, innovating incrementally may blind firms towards technology and product category leaps (O'Reilly and Tushman 2004). This may lead to what Leonard-Barton (1992) calls the "capabilityrigidity paradox". An excessive focus on gradual product improvement may imply technological exhaustion in the market in which firms compete for developing new products (Lee and Ryu 2002). Eventually, firms need to incorporate both incremental and radical approaches to new product development into their strategy.

A last example relates to conflicting requirements for chief marketing officers who are supposed to have creative flair as well as financial know-how (Quelch 2005), which is reflected in such different tasks as marketing controlling, and advertising. The
"Chief Marketing Officer's Dilemma" (McEwen 2008) is further reinforced by striving for customer engagement, which depends on both communicating and delivering the brand promise. While the first half of the input factors (communicating brand promise via advertising and marketing) is easily controlled, the second half depends on employee engagement (delivering upon brand promise via employees and operations). Combining both is likely to increase profitability (McEwen 2008).

These examples underscore the existence of conflicting marketing strategies which poses a dilemma for marketing managers and require a balance use of tools, procedures, resource endowments, structures, and supportive contexts. While the marketing literature has provided us with a wealth of suggestions as to how single elements in the implementation process can be optimized or which frameworks to use, the question of how tradeoffs between different strategies can be overcome in the implementation process has been largely ignored. One exception is the seminal work by Kyriakopoulos and Moorman (2004) and its extension by Menuc and Auh (2008), who point to the role of market orientation in integrating 'marketing exploitation strategies' and 'marketing exploration strategies'. The former refers to strategies that primarily involve improving and refining current skills and procedures associated with existing marketing strategies, including current segments, positioning, distribution, and other marketing mix strategies. Marketing exploration, on the other hand, "relates to strategies that primarily involve challenging prior approaches to interfacing with the market, such as a new segmentation, new positioning, new products, or new channels" (Kyriakopoulos and Moorman 2004: 221).

This research follows the exploration vs. exploitation paradigm and explicitly adopts an implementation focus, which redefines marketing strategy implementation as the capability to translate intrinsically conflicting demands into designs and toolsets that help to overcome marketing dilemmas. Drawing principally on the management literature, we focus on how marketers rely on structural and temporal solutions to solve implementation problems. We refer to the notion of 'ambidexterity' which originally relates to "the power of using two hands alike" (Oxford English Dictionary). The concept has first been applied to managerial contradictions by Duncan (1976) and has meanwhile entered various streams of research, like the strategic management 
literature on alignment versus adaptability (Gibson and Birkinshaw 2004), the operations management literature on flexibility versus efficiency (Adler, Goldoftas, and Levine 1999) or the innovation management literature on radical versus incremental, innovation (Tushman and O'Reilly 1994; Danneels 2002; O'Reilly and Tushman 2004). Strikingly, the marketing arena has largely ignored this promising stream of research.

Against this backdrop, this paper has three objectives: First, it is among the first to apply the concepts of exploration, exploitation, and ambidexterity to the implementation of marketing strategies. Second, it analyzes different categories for implementing ambidexterity and suggests how various types may be best coordinated. In doing so, it provides novel insight as previous studies have only very rarely analyzed different types of ambidexterity in a single study. Third, it offers a multi-level and temporal framework that synthesizes previous research on ambidexterity and prepares the ground for some promising research avenues in marketing. The rest of the paper is structured as follows: In the next section, we provide a brief review of the literature on exploration and exploitation, which we will apply as a conceptual lens to redefine marketing dilemmas. Subsequently, we describe variants of ambidexterity which have been suggested to balance the dual processes of exploration and exploitation. This leads to our revised framework of ambidexterity, which we use to empirically investigate tools and procedures to support the implementation of seemingly conflicting marketing strategies. We present the research design, findings from four cases and discuss the results of our analysis. Finally, we identify some avenues for future research and managerial implications.

\section{The Role of Ambidexterity as a Framework for Solving Marke- ting Dilemmas}

Most marketing dilemmas can be reframed by adopting the exploration versus exploitation lens (March 1991) that has attracted a large number of researchers in diverse fields of research (Birkinshaw and Gibson 2004; He and Wong 2004; Benner and Tushman 2003; Jansen, Van den Bosch, and Volberda 2005; Greve 2007). 'Exploration' refers to experimentation with new alternatives, having returns that are uncertain, distant, and often negative. In contrast, 'exploitation' describes the refinement and extension of existing competencies, technologies, and paradigms, exhibiting returns that are positive, proximate, and predictable. Keeping with the basic idea of March, most subsequent studies have focused on the organization or the business unit as the respective level of analysis (March 1991; O’Reilly and Tushman 2004, 2007; Lavie and Rosenkopf 2006). However, terms have been used somewhat sloppily, invoking a variety of associated concepts to convey the nature of exploration and exploitation. For instance, exploitation has been associated with operational efficiency, control, and reliability (Porter 1996; Deming 1981; Juran and Gryna 1988). Similar confusion exists when exploration is differentially described as involving innovation, risk taking, invention, new capability building, etc. (Benner and Tushman 2003). As interest grew further, exploration and exploitation became widely popular phrases, capturing the fundamental tension in virtually any domain of organizational adaptation (McGrath 2001). A related discussion of organizational learning processes also questions whether companies should engage in different types of innovation in order to maximize their outputs ( $\mathrm{He}$ and Wong 2004; Jansen, Van den Bosch, and Volberda 2005). While a variety of innovation types is clearly seen as important, mixing them has often been considered difficult - equally difficult as the combination of seemingly contradictory marketing strategies. This has also been the customary tenet of strategists who argued that mixing low-cost and differentiation strategies is likely to result in lock in or "stuck-in-the-middle" positions (Porter 1980: 41) with "firms that are not particularly excellent at any thing" (Miller and Friesen 1986: 42). However, from a strategic perspective, the strict opposition has been relieved as both Porter (1996) and others think that it is possible to "play the spread" (Day 1989). Further input into the dynamic interplay of conflicting strategies comes from the punctuated equilibrium model of change (Adner and Levinthal 2002) which describes different interacting modes of change and depicts organizations as evolving through long periods of stability (equilibrium periods) punctuated by relatively short outbursts of fundamental change (revolutionary periods). Researchers have suggested that firms following this pattern are more successful (Miller and Friesen 1984) because they balance reactions to both inertial and disruptive forces. Indeed, temporal cycling be- 
tween long periods of exploitation and short bursts of exploitation has been identified as a viable balancing mechanism that may be both logical and practical (Brown and Eisenhardt 1997; Gupta, Smith, and Shalley 2006).

While early studies within the exploration versus exploitation paradigm tell us that the two are rather exclusive, more recent research has emphasized the simultaneousness of exploitative and exploratory activities and their joint impact on performance ( $\mathrm{He}$ and Wong 2004; Auh and Menguc 2005; Rothaermel and Deeds 2004). Indeed, initial suggestions have been made to structurally separate exploitation and exploration within different business units in order to increase organizational performance (Duncan 1976). In addition, punctuated equilibrium theory convinces us that both types are inseparable and lead to performance enhancements if pursued alternately, i.e. via temporal separation (i.e. Gersick 1991).

Paradoxes or dilemmas have long been discussed in the literature (Thompson 1967; Burns and Stalker 1961), However, it is only recently that the concept of the 'ambidextrous organization' (Lewis 2000; Tushman and O'Reilly 1996; Katila and Ahuja 2000; Birkinshaw and Gibson 2004; Raisch and Birkinshaw 2008) provided first insights into coexistence and interdependencies of potentially conflicting objectives. While the term ambidexterity has been used in different contexts, it has largely dealt with the twin concept of exploration versus exploitation in management-related studies (March 1991; Levinthal and March 1993; Danneels 2002; Benner and Tushman 2003; Jansen, Van den Bosch, and Volberda 2005).

Here, we introduce the idea of ambidexterity as a conceptual framework for implementing inherently contradictory marketing strategies. In the literature, one of the common definitions of ambidexterity relates to the "pursuit of both exploration and exploitation via loosely coupled and differentiated subunits or individuals, each of which specializes in either exploration or exploitation" (Gupta, Smith, and Shalley 2006: 693). For our purposes, this definition is somewhat imprecise as ambidexterity can be understood as both, simultaneous or sequential balance. Typically, the former is captured in traditional definitions of ambidexterity while the latter is suggested by punctuated equilibrium theory (Tusman and Romanelli 1994; Gersick 1991; Burgelman 2002) or temporal sequence approaches (e.g. Sig- gelkow and Levinthal 2003). Contrary to other studies, we explicitly use the notion of 'punctuated ambidexterity' as a sequential approach to balancing contradictory marketing strategies. Thus, our understanding is closer to He and Wong's (2004: 483484) research which defines ambidexterity in relation to technological innovation: "We extend the exploration versus exploitation construct to define ...two generic dimensions (1) an explorative innovation dimension to denote [...] activities aimed at entering new product-market domains, and (2) an exploitative innovation dimension to denote [...] activities aimed at improving existing market positions." Here the authors keep their definition open to include both temporal and sequential coordination mechanisms.

While different variants of ambidexterity have been discussed in the literature, we know relatively little about the systematic nature of implementing ambidexterity in an organization, and our ability to interpret the differences between various forms from a rigorous theoretical vantage point is limited. Therefore, we build on existing research in strategic management and organization theory to develop a novel framework based around the dimensions of coordination level and coordination logic by which different approaches to strategy implementation are highlighted.

The first of these dimensions, namely the level of coordination, has a well-established tradition in the organization theory literature (Klein, Dansereau, and Hall 1994). Here, we refer to the levels of the individual and the organization and follow the quest by Simek (2009) to investigate multiple levels of ambidexterity. As for the organizational level, we consider ambidexterity a result of splitting the responsibilities for different types of activities between business units. Thus, while decision-making remains within the organizational or corporate level, the implementation of ambidexterity occurs within business units with differentially allocated strategy variants. We further refer to the individual level, because the individual employee impacts different strategies (Birkinshaw and Gibson 2004) and their implementation success. The second dimension, namely the distinction between simultaneity and sequence, contrasts the original ambidexterity concept with that of temporal separation, i.e. punctuated ambidexterity where organizations balance the pursuit of different marketing strategies over time. By integrating these dimensions, it is possible to 
identify four generic types of ambidexterity which facilitate the implementation of contradictory marketing strategies (Figure 1). We discuss each of these variants in turn, and show how they relate back to prior research.

\section{Figure 1: Variants of Ambidexterity}

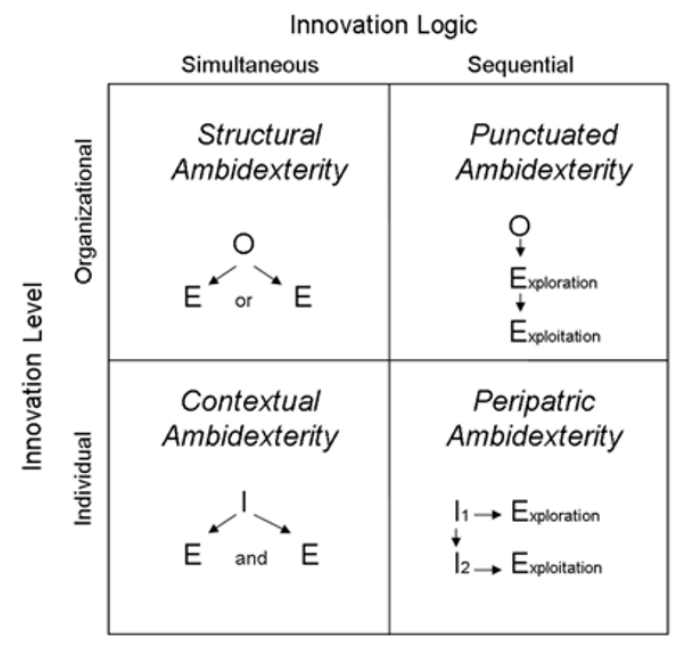

\subsection{Structural Ambidexterity}

Marketing strategists have typically resolved the tension between exploration and exploitation by separating them in two different parts of the firm (e.g., marketing vs. sales; marketing vs. R\&D; marketing vs. service). The first idea of structural separation is influenced by Duncan who argued that companies need to put in place 'dual structures' in order to manage conflicting demands (Duncan 1976). For instance, $R \& D$ and business development are given responsibility for new product development while the core business units focus on alignment and exploitation. In this vein, McDonough and Leifer (1983) suggested that organizations use several structures simultaneously because the challenges they face are so dramatically different that they cannot be managed within one organizational unit. Similarly, Christensen and Raynor (2003) proposed that established companies could pursue a disruptive innovation only in a separate business unit. Taking this further, Carson (2007) discusses the scope and required control mechanisms for outsourcing new product development entirely - an extreme form of structural separation.

Empirical research has further identified that structural separation usually occurs at different levels of the firm, e.g., between headquarters and subsidiaries or global teams and centres of excellence. Alter- natively, structural separation can be achieved by separating functions of a multi-product firm or by creating functions with a particular orientation. For instance, $R \& D$ is more oriented towards exploration while production units normally focus on exploitation. Related to the overall balance of strategies, the most common tenet has been to structurally separate business units: some with a focus on explorative innovation and others specializing in exploitative innovation (e.g. Ambos and Schlegelmilch 2005; Floyd and Lane 2000; Volberda 1998; O’Reilly and Tushman 2004; Benner and Tushman 2003). For instance, structural separation is undertaken by most large software companies which externalize specialist teams to develop revolutionary codes in distinct locations.

With respect to implementation issues, structural separation is not without limits (Birkinshaw and Gibson 2004; Adler, Godolftas, and Levine 1999). Separation can lead to isolation of particular units as innovative ideas will not be transferred and integrated across the company. Where new product development is outsourced, idea transfer and integration issues appear to be particularly pertinent. Further, due to the nature of its static approach of allocating contradictory tasks, units may loose their incentives and turn inert over time. On the other hand, exploitation-oriented structures may lack creative outbursts, which may also result in inertia. Because of the inherent difficulties that arise from balancing exploration and exploitation, it has been suggested to adopt a longitudinal perspective where a unit's focus changes over time.

\subsection{Punctuated Ambidexterity}

Organizations may also disentangle different strategic marketing tasks by separating them over time. Major emphasis is placed on organizational units that focus on one type of strategy one day, and on a different set of innovations at another point in time (Brown and Eisenhardt 1997; Puranam, Singh, and Zollo 2006). Thus, organizations temporally separate between exploration and exploitation. For instance, the same decision unit may use a mechanistic structure for making routine decisions and then shift to an organic structure for making non-routine decisions.

In the case of product development, temporal fluctuations may be best suited to cope with changes in technological jumps or breakthroughs which are likely to interpenetrate long periods of incremental 
product development. In this situation, a whole unit adapts to the requirement of specific contingencies. Similarly, Siggelkow and Levinthal (2003) suggest that units switch over time by adopting more separated organizational design at one time and more integrated ones at another. These designs may differentially relate to information transfer and knowledge generation and, thus, have an impact on new product development rates.

Occasionally, units or teams move from sales to service function or change from research-driven to commercial orientations. For instance, the RBC Financial Group in Canada is the largest bank as measured by assets and market capitalization and one of North America's leading diversified financial services. In order to become more competitive, RBC realized that some of their units had to become more market-oriented. Management started a process whereby, over time, employees sensed that the culture was fundamentally changing. Their ideas were given due consideration, and they were being rewarded for market-oriented activities (Dobni 2006). One of the advantages of these shifts is that it prevented corporate units from turning inert. It also increased inter-departmental communication which has been identified as vital for successful strategy implementation (Forman and Argenti 2005). However, there are also certain drawbacks, for instance, the ability to fluidly change organizational attributes and managerial approaches, with respect to strategic success criteria and incentive systems.

\subsection{Contextual Ambidexterity}

The organizational literature also suggests that ambidexterity emerges when leaders in a business unit develop a supportive context. The resulting type of contextual ambidexterity, which was formally introduced by Birkinshaw and Gibson (2004), is seen as the behavioral capacity to simultaneously demonstrate alignment and adaptability (Lubatkin, Simek, Lin, and Veiga 2006; Mom 2007; Carmeli and Halevi 2009; Guettel and Konlechner 2009). Indeed, contextual ambidexterity differs markedly from structural ambidexterity because it is "...a dual capacity ... woven into the fabric of an organization on the individual level". Instead of focusing on dual structures or on changing tasks for business units, organizations reconcile conflicting demands by building a set of processes, systems or contexts that enable and encourage individual employees to make their own judgement as to how to divide their time between conflicting demands. For instance, marketing managers decide whether they engage in new business development, service or sales activities, e.g. by involving customers with a need for ongoing incremental product development. Here, the contextual variant remains a set of stimuli that motivate marketing managers to act in a certain way.

Previous research has acknowledged the role of managers in enabling and developing conditions for ambidexterity (Gibson and Birkinshaw 2004; Smith and Tushman 2005; Lubatkin, Simek, Lin, and Veiga 2006). Building predominantly on a leadership approach, studies have documented the importance of contextual leadership that helps to balance requirements posed by contradictory activities and, consequently, sustains business unit performance (Osborn, Hunt, and Jauch 2002). Among scattered insights there is consensus on a few mechanisms that help to support contextual ambidexterity. For example, Tushman and O'Reilly (1997) argue that it is driven by internal processes that enable managers to handle large amounts of information and decision alternatives to deal with conflicts. Carmeli and Haleyi (2009) suggest that managers should make active use of conflicts rather than avoiding them. As a consequence, behavioral complexity, i.e., the capacity to adopt multiple leadership roles and change between them in selective contexts, is seen as primordial (Lubatkin, Simek, Lin, and Veiga 2006). Most of the previous guidelines seem intuitively simple, but little has been said about their concrete implementation. As Mom (2007) remarks, there is clearly a lack of conceptually and empirically validated understanding about exploration and exploration at the managerial level of analysis. This is surprising given the promising potential of related literatures on organizational learning and top management research. Furthermore, none of the existing work has yet related to marketing tasks. Switching between different contextual requirements seems indeed difficult as managers lack the ability of integrating exploitation into their mindset. Hence, they have to be substituted in order to pursue consolidation or exploitation strategies. This is captured within the last cell of peripatric ambidexterity.

\subsection{Peripatric Ambidexterity}

While the previous types of separation are well anchored in the existing literature on ambidexterity, no explicit reference has yet been made to coordi- 
nating marketing strategies by exchanging the top management or founding team. For this variant, we initiate the notion of 'peripatric ambidexterity', a term borrowed from genetics. This specifies the formation of a new species through during evolution and is often tied to the idea of a founder who develops a new population within an isolated niche (Mayr 1942). In the business world we can find some analogies which emphasize the substitution of one 'species' by another. Take the example of Nissan and Renault, now headed by Carlos Ghoshn. The manager has instilled a vision of innovative and exploratory leadership at the two companies that his predecessors failed to achieve. However, people presently ask whether he might be better off in the saviour rather than the consolidator and incremental adapter role. Thus, management may again have to change or evolve further. Similarly, when Goodyear was confronted by Michelin's introduction of the radial tire, Goodyear's senior management team first focused on the existing product and avoided radical challenge. When they finally introduced the radial tire, Goodyear completely shifted from bias-ply tires to radicals. This strategic shift at Goodyear led to the creation of a new senior management team (Virany, Tushman, and Romanelli 1992; Smith and Tushman 2005).

The literature on leadership covers this phenomenon with reference to the 'human trait of ambidexterity' (Lubatkin, Simek, Lin, and Veiga 2006). Further insight comes from research on founding teams and their prior affiliations which are presumed to shape new firm behaviors (Beckman 2006). Executive behavior is supposed to be driven by past insights and experiences. Thus, previous career experiences shape the range of action that is available to formulate and implement strategies, i.e., engage in either explorative or exploitative behavior (Boeker 1997; Kraatz and Moore 2002). While a variety of perspectives stimulates exploration, a singular company affiliation is likely to improve existing routines and consolidate existing capabilities.

The size of the firm may play another important role for choosing peripatric ambidexterity. While large firms with a variety of business units are likely to pursue both exploration and exploitation, an entrepreneurial firm exists as a single business unit. Thus, the choice of a homogeneous team defines the corporate orientation to strategy variants. Contrary to punctuated ambidexterity, the peripatric version posits that it is difficult for individuals or teams to change behaviors. Once they surpass a critical size, only a few managers from the original founding team are normally able to manage the shift. As suggested in situational leadership theories, it is much easier to find the manager and identify situational fit (Fiedler 1967). Thus, a firm needs to exchange its top management if it intends to implement a drastic change in corporate strategy.

In summary, the description of the four variants of ambidexterity has shown that each of them is a suitable solution for not only balancing exploration and exploitation within an organization, but also for solving concrete marketing dilemmas by implementing ambidextrous designs. Table 1 summarizes the major insights from the literature, highlights selected marketing dilemmas and implementation categories, and presents the few existing insights on the practice of ambidexterity. As these insights are largely anecdotal, our study is largely exploratory (Churchill and Iacobucci 2005; Srnka and Koeszegi 2007) and investigates implementation categories in more detail.

\section{Research Design}

The findings presented below are part of a larger research project on ambidextrous innovation in global firms. In the first (and ongoing) stage of the project, we have conducted 50 interviews in Germany, Austria, France, The Netherlands, Switzerland, and the UK. Industry sectors included banking, engineering, automotive, information technology, consulting, fast moving consumer goods, and biochemistry. In the second stage, we purposefully re-contacted four firms (Patton 1990), Apple, Deutsche Bank, Deloitte, and Celltech (UCB), and conducted indepth interviews to focus more specifically on how diverse marketing strategies can be best implemented by using ambidextrous designs. More detailed information on the research design can be found in the appendix.

\section{$4 \quad$ Presentation of Findings}

We start the presentation of findings by reporting the results of our content-analysis per firm (Miles and Huberman 1984). The structure of each case presentation begins with a short overview of the firm and major conflicts or dilemmas. We discuss relevant implementation categories of ambidextrous designs in detail and illustrate how they support the combination of controversial marketing strategies. 
Table 1: Major Approaches to Ambidexterity, Selected Marketing Dilemmas, and Implementation Criteria

\begin{tabular}{|c|c|c|c|c|}
\hline & $\begin{array}{l}\text { Structural } \\
\text { Ambidexterity }\end{array}$ & $\begin{array}{l}\text { Punctuated Ambi- } \\
\text { dexterity }\end{array}$ & $\begin{array}{l}\text { Contextual Ambidex- } \\
\text { terity }\end{array}$ & $\begin{array}{l}\text { Peripatric Ambi- } \\
\text { dexterity }\end{array}$ \\
\hline Major Studies & $\begin{array}{l}\text { Duncan (1976); O’Reilly } \\
\text { and Tushman (2004); } \\
\text { Tushman and O'Reilly } \\
\text { (1997) } \\
\text { Jansen, Van den Bosch, } \\
\text { and Volberda (2009) }\end{array}$ & $\begin{array}{l}\text { Punctuated equilib- } \\
\text { rium (Gersick 1991; } \\
\text { Tusman and Ro- } \\
\text { manelli 1994; Burgel- } \\
\text { man 2002) } \\
\text { Temporal separation } \\
\text { (Siggelkow and Levin- } \\
\text { thal 2003) }\end{array}$ & $\begin{array}{l}\text { Gibson and Birkinshaw } \\
\text { (2004); Smith and } \\
\text { Tushman (2005); } \\
\text { Lubatkin, Simek, Lin, } \\
\text { and Veiga (2006); Mom } \\
\text { (2007); Carmeli and } \\
\text { Halevi (2009) }\end{array}$ & $\begin{array}{l}\text { Genetics (Mayr, } \\
\text { 1942) } \\
\text { Leadership research } \\
\text { Burns (1978), Bass } \\
\text { (1985) }\end{array}$ \\
\hline $\begin{array}{l}\text { Definition of Ambidex- } \\
\text { terity }\end{array}$ & $\begin{array}{l}\text { "Ambidexterity refers to } \\
\text { the synchronous pursuit } \\
\text { of both exploration and } \\
\text { exploitation via loosely } \\
\text { coupled and differenti- } \\
\text { ated subunits or indi- } \\
\text { viduals, each of which } \\
\text { specializes in either ex- } \\
\text { ploration or exploita- } \\
\text { tion." (Gupta, Smith, } \\
\text { and Shalley 2006: 698) }\end{array}$ & $\begin{array}{l}\text { "Temporal cycling be- } \\
\text { tween long periods of } \\
\text { exploitation and short } \\
\text { bursts of exploration" } \\
\text { Gupta, Smith, and } \\
\text { Shalley 2006: 693) }\end{array}$ & $\begin{array}{l}\text { "Contextual ambidexte- } \\
\text { rity is the behavioral ca- } \\
\text { pacity to simultaneously } \\
\text { demonstrate alignment } \\
\text { and adaptability across } \\
\text { an entire business unit" } \\
\text { (Gibson and Birkinshaw } \\
\text { 2004: 209) }\end{array}$ & $\begin{array}{l}\text { "Change towards a } \\
\text { new evolutionary } \\
\text { period of the firm } \\
\text { which is inextricably } \\
\text { linked to a CEO or } \\
\text { Top Management } \\
\text { Team" (inspired by } \\
\text { Mayr, 1942) }\end{array}$ \\
\hline Description & $\begin{array}{l}\text { Dual structures, differ- } \\
\text { ent units focus on dif- } \\
\text { ferent types of activities } \\
\text { or challenges }\end{array}$ & $\begin{array}{l}\text { Single units, shifting } \\
\text { focus over time, i.e. } \\
\text { concentrating sequen- } \\
\text { tially on different types } \\
\text { of marketing }\end{array}$ & $\begin{array}{l}\text { Individuals in business } \\
\text { units, who decide on } \\
\text { which type of activity } \\
\text { they want to focus }\end{array}$ & $\begin{array}{l}\text { Top Management } \\
\text { Team / CEO focuses } \\
\text { on one particular } \\
\text { type of strategy at a } \\
\text { given time }\end{array}$ \\
\hline $\begin{array}{l}\text { Contribution of Ambi- } \\
\text { dexterity Framework to } \\
\text { Resolving Marketing } \\
\text { Dilemma }\end{array}$ & $\begin{array}{l}\text { Combination of brands } \\
\text { and products which } \\
\text { may otherwise canni- } \\
\text { balize each other; tar- } \\
\text { geting of incompatible } \\
\text { customer segments (e.g. } \\
\text { Deutsche Bank vs. } \\
\text { Maxblue Investment } \\
\text { Platform; SAP Soft- } \\
\text { ware Development ) }\end{array}$ & $\begin{array}{l}\text { Disruptive technology } \\
\text { changes versus incre- } \\
\text { mental product inno- } \\
\text { vation } \\
\text { (e.g. Siemens VDO has, } \\
\text { at a point in time, ac- } \\
\text { counted for 90\% of all } \\
\text { innovations) }\end{array}$ & $\begin{array}{l}\text { Short-term balance of } \\
\text { existing and new mar- } \\
\text { keting trajectories } \\
\text { (e.g. Google with indi- } \\
\text { vidual responsibility for } \\
\text { radical product innova- } \\
\text { tion and adjustment) }\end{array}$ & $\begin{array}{l}\text { Sales-driven vs. con- } \\
\text { solidation driven } \\
\text { marketing; emotion- } \\
\text { nal versus informa- } \\
\text { tive marketing (e.g. } \\
\text { consolidation of Ger- } \\
\text { man Metallgesell- } \\
\text { schaft by Kajo Neun- } \\
\text { kirchen or Renault/ } \\
\text { Nissan with Carlos } \\
\text { Ghoshn) }\end{array}$ \\
\hline $\begin{array}{l}\text { Implementation of Am- } \\
\text { bidextrous Designs }\end{array}$ & $\begin{array}{l}\text { Strong autonomy; } \\
\text { cross-unit relationships } \\
\text { (Raisch 2008); integra- } \\
\text { tion through teams and } \\
\text { organizational mecha- } \\
\text { nisms (Jansen, Tempe- } \\
\text { laar, Van den Bosch, } \\
\text { and Volberda (2009), }\end{array}$ & $\begin{array}{l}\text { Focus on specialized } \\
\text { skills closely tied to the } \\
\text { requirements of one } \\
\text { activity or period. } \\
\text { Change management }\end{array}$ & $\begin{array}{l}\text { Behavioral complexity } \\
\text { (Hambrick and Mason } \\
\text { 1994) } \\
\text { Organizational context } \\
\text { (Ghoshal and Bartlett, } \\
\text { 1994), Culture (Ne- } \\
\text { manich and Vera 2009) }\end{array}$ & $\begin{array}{l}\text { No explicit studies as } \\
\text { construct has not yet } \\
\text { been used in the lit- } \\
\text { erature }\end{array}$ \\
\hline $\begin{array}{l}\text { Selected Implementa- } \\
\text { tion Categories from the } \\
\text { (Marketing) Strategy } \\
\text { Literature }\end{array}$ & \multicolumn{4}{|c|}{$\begin{array}{l}\text { - Structural variables: company's marketing function, control systems, policy directives (Bonoma and } \\
\text { Crittenden 1988); formal firm structure and networks of informal communications (Franckwick, } \\
\text { Ward, Hutt, and Reingen 1994); } \\
\text { - Behavioral variables: skills, resource allocation, ability to develop informal structures (Bonoma and } \\
\text { Crittenden 1988); } \\
\text { - Interpersonal processes: strategic consensus and autonomy, leadership and implementation styles, } \\
\text { communication (Noble and Mokwa 1999), shared understanding (Woolridge and Floyd 1989); } \\
\text { - Individual-level processes: cognition, organizational roles, commitment (Noble and Mokwa 1999); } \\
\text { - Managerial levers: goals, organizational structure, leadership, communications, incentives (Noble } \\
\text { 1999) }\end{array}$} \\
\hline
\end{tabular}


We continue with a discussion of commonalities across cases and compare findings with relevant insights from the literature.

\subsection{Q110 - Deutsche Bank der Zukunft: Structural Ambidexterity}

Deutsche Bank, with headquarters in Frankfurt/Germany, is one of the leading financial institutions with some 80,000 employees in more than 72 countries. With a large presence in Europe, the Americas, Asia Pacific and the emerging markets, the bank offers financial products and services for corporate and institutional clients along with private and business clients. In 2005, having faced hugely negative customer satisfaction and retention rates, especially with outsourcing its online subsidiary, Deutsche Bank24, the company decided to break new grounds. Driven by the Private Client and Asset Management division (PCAM) and its subdivision Private \& Business Clients (PBC), which provides private individuals and small to medium-sized businesses with a full range of traditional banking products, the company decided to launch a new innovative subsidiary in the city centre of Berlin, Germany. The creation of "Q110 - Deutsche Bank of the Future", as it is referred to, was largely marketing-driven and (originally) had the sole purpose of bringing customer satisfaction rates to new heights. Q110 is tangibly different from corporate headquarters and other subsidiaries as it draws inspiration from unusual ideas and strikes out new paths - often involving innovative technology. Right from its inception, the subsidiary was created as a translucent building, integrating shops, service offerings, a lounge for relaxation and some 1260 square meters for interaction. No counters are allowed to interfere with the boundary-free interior design and the open spirit of the unit's team. As one interviewee (B3) put it: "Each time we create an encounter, we do so exactly in the way the customer prefers it....this could be a coffee in the lounge, a product show on one of the oversized TV screens, a guided tour ....or, if the customer prefers, a quiet room. And even more, the customer does not necessarily come here to demand a banking service, but rather because he likes the atmosphere or looks for inspiration and design products." Thus, the centre is characterized by customer orientation, proximity and approachability, which also includes opening hours beyond the expected.
When launching structural separation, one of the major challenges of the new subsidiary was to introduce new customer and service experiences and market them differently. However, this new marketing approach needed to be compatible with a traditionally conservative approach to banking and financial services. Ambitiously formulated (B2), "The objective was to win all private customers for our subsidiary." Thus, within the overall conglomerate of Deutsche Bank, it was clearly decided that Q110 was to act beyond traditional structures supporting a context of creativity. While the structural separation of the unit was one issue, from a corporate perspective, it was even more important to integrate different marketing strategies and underlying value systems as both, Q110 and more exploitative subsidiaries were to coexist under the umbrella of Deutsche Bank AG. The activities launched by Deutsche Bank to implement structural ambidexterity can be described in terms of the nine implementation categories (see Table A.2 in the Appendix).

Goal-setting is an important aspect of a firm's implementation process and clear objectives should be communicated (Noble 1999). At the stage of implementing Q110, the formulation of strategic objectives was in line with the exploratory function of the unit, e.g., its overachieving goal of customer development and whole-hearted dedication to customer satisfaction. The implementation literature also emphasizes that without knowledge of the strategic vision, functions would not be able to implement a marketing strategy within a broader context (Noble 1999). Initially, there were no immediate financial constraints, which would have been imposed on a more exploitative unit. In this sense, achieving ambidexterity created paradoxical situations because the short-term efficiency and control focus of headquarter-dominated subsidiaries was at odds with the long-term experiential focus of Q110 (see also Floyd and Lane 2000).

In terms of structure, strategy implementation is often difficult when units are unequally affected or represented, e.g., when one unit is considered more important than the other. However, separating Q110 as a different unit from corporate headquarters was not seen as a major issue (B5: "We all work for Deutsche Bank, we do not talk about Q11o to our customers.") While structural separation was driven by the top management, with people working in clearly distinct locations, employees' mindsets were not completely detached from other units. In part 
this is due to the overall spirit and vision Deutsche Bank integrates in the different units. Further, an ongoing communication process with colleagues of other units reflects the typical work flow when assignments and clients are handed over. Formal meetings are complemented by informal communication, especially when the objective is serving the customer better (B6:"When there is a customer, and even if we do not have the time, we talk to our colleagues and we try to constantly be in touch to see who has some availabilities... we normally find a solution").

Incentives systems are important tools in implementing strategy and include both monetary and non-monetary rewards (Walker, Churchill, and Ford 1977). Within Q110 no special financial incentives were put in place (e.g. B4: "We do not receive any bonus payments simply because we work for Q11o...even though the work is quite different and we have long working hours, including even Saturdays.") However, what was clearly mentioned were immaterial incentives arising both from the team atmosphere and, most prominently, from future career perspectives (e.g. B3: “...many people, after they left Q11o have continued their management career somewhere else within Deutsche Bank. Having worked for Q11O is apparently seen as a preparation for major career jumps"). Apart from being an individual incentive, the promotion of people into other units serves a means of integration and transferring exploratory knowledge to exploitative units.

The organizational context, e.g. the systems and processes that define the context for ambidexterity is strongly related to individual empowerment through leadership. This reflects the criteria of discipline and stretch as illustrated by Ghoshal and Bartlett (1994), who propose that employees voluntarily strive to meet expectations. But more importantly, organizational stretch induces them to strive for more, rather than less ambitious goals. While employees work in a structurally separated context, it is these criteria that facilitate contextually ambidextrous behaviors within their explorative unit. It seems as if this has been an objective from the beginning as recruiting policies did not only focus on exploration-oriented people but on diversity. For instance, a formal banking education was not part of the predominant catalogue of criteria. (B3: "I was first a carpenter, then I had a traineeship with the bank, did several things in between and now I am here. What they require is more a certain attitude and willingness to learn than a formal education. However, this has changed a bit in the meantime and I think everybody now builds on an apprenticeship with Deutsche Bank"). The diversity in employee background and culture was seen as one requirement to increase behavioral complexity. This is vital in a context that incorporates all sorts of service offerings beyond the typical banking products.

The case of Deutsche Bank was initially selected to investigate structural ambidexterity, which occurs on several levels of the firm. For instance, it was the driving element to distinguish both between corporate divisions and between sub-divisions like Private and Business Clients (PBC) and Asset and Wealth Management (AWM). In several geographic regions, AWM is placed in attractive locations and buildings clearly distant from the PBC functions. Spatial/geographical separation also presented the founding principle for Q110 in Berlin, which was dislocated from the corporate functions in Frankfurt/Main. However, like a 'nested design', Q110 does not only serve as an example of structural separation, but is also built on contextual ambidexterity and, to a minor degree, incorporates elements of punctuated ambidexterity (see further explanation in the cross-case discussion).

\subsection{Deloitte Consulting: Contextual Ambidexterity}

In 1995, the partners of Deloitte Touche Tohmatsu voted to create Deloitte \& Touche Consulting Group (later Deloitte Consulting) which, after creation, remained part of the overall Deloitte group. By integrating skills from across the firm, Deloitte answers clients' demands for single-source solutions. Globally, Deloitte is present in over 130 countries and employs more than 90,000 people. Consulting services are focused on three main areas: Strategy \& Operations, Technology Advisory Services, and Human Capital Advisory Services. In terms of revenues, the company achieved $\$ 6.3$ billion in 2008 .

The need for ambidextrous designs was driven by several developments within the consulting industry, most notably customer demand, information technology, changing regulation, and increased competition. These trends confronted managers with the challenge to increasingly focus on both exploration and exploitation activities. Within Deloitte Consulting, this challenge is most prevalent on the partner and manager level (D1: "The partner role is 
naturally one of developing the business, but you also have to capitalize on your existing abilities and current projects, and this is precisely the difficulty - doing two things that do not quite go well together"). Indeed, it is clearly expected that partners conduct both exploitative (e.g. striving for costefficiency) and explorative activities (anticipating industry changes) to deal with current and future requirements of the firm. As front-line experts, they are so close to customers and their specialized experience makes them ambassadors of their company's services. At the same time, they need to extend previously successful projects and procedures with seemingly minor modifications to fit the new clients. In the firm, roughly $30 \%$ of the work time is dedicated to new developments and research, while the dominant focus remains on working with the client. However, managers and partners have leeway in deciding upon their current focus. Ambidextrous challenges also occur in the capability-based marketing approach of the firm. In building trust with clients and potential employees, knowledge and competence are seen as major drivers. This implies that both existing competencies need to be nurtured, while new knowledge is required to signal cutting-edge technical expertise.

In order to implement these challenges, a variety of implementation instruments was used. On a strategic level, the overall goals of the firm do not change while it continuously reorients itself towards market demands. Growth is certainly an issue and the firm tries to proportionally manage growth while expecting profitability rates to rise accordingly. This implies a multi-market approach (D4: "It also depends on the location, some are exciting in terms of firms coming into the country, others are more established; you definitely do not want to be limited to local markets especially if you look at markets that are definitely going to grow [...] but this requires flexible adaptation").

When this type of flexible adaptation has been successfully achieved, "every individual in a unit can deliver to existing clients ... but at the same time every individual is on the lookout for changes in the task environment, and acts accordingly. This is potentially a more sustainable business model ... because it facilitates the adaptation of an entire business unit, not just the separate units or functions responsible for new business development" (Gibson and Birkinshaw 2004: 211). Within Deloitte, this is reflected in their 'multiple market approach', i.e., offering global services adjusted to local contexts. This requires that managers individually adjust behaviors to national clients while representing a global firm. The succinct balance arises from continuous adaptation and re-adaptation.

In doing so, continuous learning is one of the major competences of the firm which does not only affect the managerial level but transcends the organization. Thus, all employees are actively encouraged to develop, improve, and refine in-depth knowledge pertaining to a certain market segment, country, culture, product, service, or internal process which is anchored in the organizational context and supported by suitable structures. The organizational context can be described according to the four elements of discipline, stretch, support, and trust (Bartlett and Ghoshal 1994). Within Deloitte, discipline is already reflected in the recruiting process where the firm is being committed to being transparent about the progress toward global goals, both for employees and the firm. Member firms, partners and employees are all united in the effort to collectively achieve these goals and help turn a shared vision into results. The development of the vision incorporates 'stretch' so as to inspire people with the abilities to organize themselves and move upwards. With regard to more exploratory activities, the value system emphasized diversity from which a broader variety of new inputs is believed to emerge. As a basic prerequisite, employees are recruited according to criteria such as openness, ability to learn and relationship skills with clients. Internally, these skills are constantly challenged and stretched to facilitate optimum careers (D4: "I always try to see the potential of people, I listen intensively, challenge them... help them, and discuss options with them"). In addition, the career path is open to focus more on technical expertise or managerial skills where people can change the percentages and requirements of explorative versus exploitative behavior. These moves are actively supported by the management which lends access to resources and interchange. Finally, the element of trust plays a particular important role not only within the firm, but also in relation to its clients. Trust is seen as the selection criteria that facilitates relationship building and longterm developments. This is also reflected in the firm's approach to culture which takes on open and supportive stance and focuses on the idea that development is a voluntary act (D1:"People want to learn. If we want to change something we need to 
explain it to them so that they see the benefits and can decide themselves which way to follow"). Culturally-driven knowledge development initiatives serve this purpose of interpersonal support and exchange as they are normally integrated into daily operations and customer needs.

In summary, the example of contextual ambidexterity shows that soft implementation factors dominate the balance of marketing strategies. This is in line with an understanding of knowledge management and capability development as voluntary actions transcending different levels of the firm.

\subsection{Celltech: Punctuated Ambidexterity}

The origin of Celltech, one of the largest biopharmaceutical companies in Europe, dates back to the year 1980, when investment funds were obtained to build up a strong foundation around diagnostics, nutritional and contract business followed by therapeutics in the late eighties. Celltech can be viewed as having four basic historical periods, which link to the balance of exploration and exploitation. First, the two different strands of biologics and therapeutics were meant to subsidize each other. Between 1990 and 1992, the future was seen in the development of innovative drugs, thus in expanding exploratory innovation of the therapeutics unit. In the third period between 1992 and 1996, resources were equally distributed to both units, while at the same time fostering a strategy of external collaboration. In this period, business units reaped off the benefits from exploiting their existing knowledge via cash milestone payments from their collaborators without selling a full interest in the downstream property rights. Finally, in 1996 the biologics division was sold. From now on, the unique focus of the therapeutics unit changed from exploitation to exploration and the success of this strategy was evidenced in a 25\% increase in share prices in 1998.

However, there were difficult challenges associated with the unit's shift between exploitative and explorative strategies. Viewed across extended periods of time, balance was achieved by maintaining three explorative (discovery of new drugs, phase one clinical trials, development of collaborative capability) and two exploitative activities (phase two and three clinical trials, management of prestige alliances, which facilitate access to world-class capabilities). The resulting question is how Celltech managed to induce and maintain this balance.
Initially, management support in developing a shared culture and language across the firm was one of the major facilitators (McNamara and BadenFuller 1999; Dodgson 1991). Emphasizing the need for exploration originated from an ongoing crisis at the end of the 1980s when the biology unit had been the major source of revenues. At that time, it was largely based on the exploitation of academic knowledge. On the therapeutics side, exploitation did not achieve sustainable revenues, and change would have to overcome the inert culture and an over-reliance on existing knowledge. External requirements from stakeholders demanded new directions and new capabilities had to be developed in order to focus on explorative product development rather than on technical excellence. One of the major associated challenges of putting these opposing strategies into place resulted in 'unlearning' old behaviors. This was seen as difficult because efforts and risks in switching from one capability to another can be substantial while necessary to substantiate marketing activities. Celltech managed to do this by applying several managerial techniques which we present with reference to our category scheme:

In terms of corporate goals, the changes within Celltech were driven by external market contingencies. Celltech's corporate strategy has been adapted over its 11 years of existence and the firm's management has defined respective 'tipping points' which characterized the shifts from more explorative to exploitative periods and vice versa (Dodgson 1991). For instance, the choice of the new therapeutics focus was driven by a new leadership efforts ( $\mathrm{C}_{\text {lit: }}$ "It came from the top. Of course, there were managers further down but the way we were going to organize ourselves came from David Bloxham (Director of Research)"; McNamara and Baden-Fuller 1999: 7). Essentially, the company's strategy has changed from being a research company to a manufacturing company to a fully integrated biopharmaceutical company developing, manufacturing and marketing drugs. Implementing these changes in the skill base, associated changes in strategy and learning processes needed to be diffused throughout the units.

The internal learning process was largely influenced by soft implementation criteria, such as culture, communications, and leadership styles: When the unit changed from a discipline and technologybased capability to explorative therapeutics, chem- 
ists were thrust together with biologist leading to differences in understanding. Disciplines that had previously worked in isolation now had to converse and train each other in the basics of their discipline. (C1: "It was quite amazing. Formerly, you were a specialist in your field... you still continued to be one but the new task was move out of the box and increase interdepartmental knowledge sharing”). An understanding of the language and mindset of each other facilitated a deeper understanding. Triggers for innovative solutions were set off through this process of developing a shared understanding at the level of bench scientists. The firm's organizational culture or 'social fabric' played a major role in determining the speed of learning a new explorative approach to innovation (Brown and Dugoid 1991). Indeed, particular attention was paid to managing exploration for new knowledge. This involved informal interaction mechanisms as staff was located in close proximity and the layout of the building was specifically designed to facilitate interactions. Supported by more formal mechanisms, like quarterly reviews, the team was forced to constantly interact with the senior management in order to formulate realistic forecasts and have new ideas bubbling up.

In terms of recruitment, changes were supported by broadening the existing skill-base $\left(\mathrm{C}_{\text {lit }}\right.$ : "The new people faced the informal and social club of the old.. it took time to integrate them but the process of learning to work together created a new knowledge base and capability within the firm"; McNamara and Baden-Fuller 1999: 11). While employees previously used to work in functional teams, they were now required to launch projects by tapping differing functional expertise within one group. Thus, diversity of knowledge and the combination of expertise was deliberately used as a driver of knowledge development. Staff from different disciplines was hired to support the formation of new team structures and infuse the unit with new resources. The required roles and skills reflected the predominant mindset of the unit at specific points in time, while a major focus was placed on extensive training support to increase expert knowledge. This was tied to individualized incentive systems which rewarded enthusiasm and commitment, whereby, the company had considerable flexibility in its employment system to allow for this. While expert knowledge remained the central recruiting criterion, it was immediately complemented by extensive training. To reward expert knowledge, the role of Principal
Scientist was created for those people wishing to concentrate on developing scientific expertise, rather than undertaking management responsibilities (Dodgson 2001: 146).

Taken collectively, the move from exploitation to exploration was considered risky, but the unit's success helped the organization to survive and grow. One of the major lessons learned was the fact that the company did not only require a change in scientific, but also in managerial capabilities in order to succeed. These relied predominantly on knowledgesharing skills. Further, systems were put in place to ensure the long-term balance between exploration and exploitation by inserting discovery projects into the life-cycles of knowledge exploitation. This helped to prevent exploration being driven out by exploitation which has often been mentioned as one of the major dangers (McNamara and Baden-Fuller 1999). In terms of the organizational context, several monitoring procedures were implemented to guarantee the ongoing success of the new strategic orientation. In 2004, Celltech was acquired by UCB while Celltech's innovation stance within the larger group remained the same.

\subsection{Apple Computer and Peripatric Ambidexterity}

In 1976, Apple was founded by Steve Jobs and Steve Wosniak. Within several months, they had produced 200 computers. Jobs made it Apple's mission to bring easy-to-use computers to the market. In 1978, the company launched the Apple II that sparked a computing revolution that drove the PC industry to $\$ 1$ billion in annual sales in less than three years. Apple quickly became the industry leader and, in 1980, launched a successful IPO. The competitive position changed in 1980, when IBM entered the PC market and Apple's market share continued to drop. In 1985, Apple removed Jobs from his operational role and handed over to John Sculley, a former Pepsi executive. Under Sculley, Apple worked to drive costs down and sustain profitability. However, in a lacklustre period during 1989-1997 Apple was nearly written off but it had an impressive and dynamic comeback after Jobs rejoined the company in 1998. The restructuring efforts continued. Between 2003 and 2008, sales multiplied to $\$ 24$ billion and it topped Fortune's 500 companies in terms of total return to share-

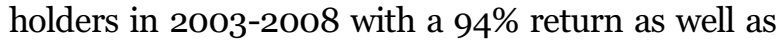


during the period of 1998-2008 with a 51\% return (Morris 2008: 68).

One thing that makes the firm special is Steve Jobs, the co-founder and CEO of Apple, who has always been a persuasive and charismatic evangelist for the company. (A4: "No, by no means is Steve Jobs a normal boss. He is in the firm, the spirit is alive, and he is always present"). While Jobs has powerfully put forward the growth of the firm, an industry-wide sales slump towards the end of 1984 caused deterioration in Jobs' working relationship with then CEO John Sculley. By the end of May 1985, following an internal power struggle and an announcement of significant layoffs, Jobs was ousted before making a triumphant return in 1997. But why has the rise and fall of Apple been so closely linked to the innovation-driven leadership style of Steve Jobs? And why did the company temporarily have to get rid of him in order to consolidate operations? One of the major explanations builds on his personality.

Jobs has always been driven by the energy to change the world with exciting new products. Fundamentally, the design and development of the Macintosh in 1984, Apple's flagship product, is an emblem of Job's entrepreneurial spirit that characterized Apple in its garage-shop days. Driven by explorative innovation strategies, Jobs unleashed the creativity of highly individualistic and talented soft- and hardware designers. He infused the development team with a renegade spirit, often shouting the battle cry, "It's better to be a pirate than join the Navy" (Sculley and Byrne 1987: 147). Indeed, the pirate metaphor was more real than fiction as Jobs, as well as his frenetic work schedule of 48-hours of straight programming and breaks with pineappletopped pizza generated a sense of shared responsibility and togetherness.

However, while the new product generated publicity, company morale was low. Apple had become a company that was too preoccupied with management and groups rather than with inspiring new products. Jobs' personal success gave way to a professional nemesis as his leadership and innovation style did not fit any longer to the company's immediate requirements. Executing a shift in strategy from exploration to exploitation was seen as a challenge for top executives. While competitive demands from the external environment left no manœuvering space, the firm's internal social structures, roles, and norms were still influenced by an explorative forward-looking management style. Human agency, in terms of a different personality, was seen as the primordial means to execute a change (consolidation) in the firm's strategy. However, once Jobs left the company, Apple became so marginal in the computer industry and losing so much money that analysts debated whether it would implode or be sold. Jobs, who returned to Apple in 1997 after years of exile, was still attracted to devices that define new categories, rather than compete in large, pre-existing industries. His comeback was seen as Apple's desperate attempt to survive one of its worst phases and the company again needed a charismatic leader who would revive its fortunes (A4: "The years in which he was not there were ok, we still had a huge hype but he was missing. When he came back in 1998, we again had all the attention"). And since Jobs himself has proved unrivalled in the art of managing disruption, he was again able to take Apple to new heights. In doing so, he built on his ability to get his employees so motivated that they maniacally achieved goals or created technology far beyond what they thought was possible.

The story of how Jobs built the Apple empire, how and why he was thrown out of it and the reasons behind his return to Apple is essentially the story of an entrepreneur and a firm's peripatric ambidexterity - a prominent corporate marketing strategy tied to a single person. It shows that a leader's personality influences a company and indeed a fundamental change can only be achieved once the leader is dismissed - or resurrected. (A4: "There will be a big bang when he is no longer there... what is obvious, the brand is tied to him, it is crazy how one person drives this firm").

In terms of implementing the current strategy, several elements were observed. Fundamentally, the firm is driven by the charisma and inspiration of one person, even though the top management has a proper function in the actual operations. But the role of a (this) $\mathrm{CEO}$ is one of the fundamental drivers for firm strategy. Building on his charisma, employees are inspired to work for the firm rather than by being attracted by impressive financial bonus systems. The company has a very hierarchic structure (A4: "You may check back with London (the European headquarters) but then, quite quickly, you are in the US") which also implies that decisions are often checked and double-checked rather than spontaneously implemented by competent 
managers. Various control systems are in place and often employees rather try to play it safe. In terms of communications, the company has an explicit nondisclosure policy and even internally, crossfunctional communication is often limited, sometimes by design, sometimes by default. In critical areas, knowledge transfer is inhibited by different locations (structural separation) in others, simply by a lack of engagement into inter-departmental communication (A5: You won't believe it but there are many areas where access is restricted and you have no idea what people are doing, you have no idea what the company is heading at").

It seems like these management principles match certain employee characteristics. People working for the firm have been describes as all "being somewhat crazy", A4) and the firm's recruiting policy might already include a self-selection process as to which people apply for a job. Once in the business, people either conform to the vision of the firm (that of Steve Job) or leave. For those who have been doing the job for a while, it is still astonishing how much they feel the daily presence of the firm leader (A5: While it looks good, it is not the touch and feel to make everybody happy ... it is rather tough because you feel obliged to function, and I say 'function' because sometimes you just have to do what you are being told. But somehow, it is strange, you do everything for a glimpse of attention"). The duality of micro-management and charismatic inspiration provides some of the driving forces for the implementation of explorative activities. While this strategy has proven successful over the past, the firm may require exploitative moves. However, with such a strong person-dominated culture and strategy, the decisive question is whether the firm is able to change. One of the major concerns is that a new CEO might change the overall orientation of the firm and, thereby, destroy what makes it special.

In summary, the four cases provide insights into how marketers could coordinate different strategies by implementing ambidextrous designs. All cases started from different contexts and highlighted different implementation criteria. While each firm applied specific implementation tools and procedures, there are several commonalities across cases, which we discuss with reference to the relevant literature.

\section{Discussion}

For every firm it is essential to achieve both growth and profitability which often hinges upon the successful implementation of marketing strategies. This includes the combination of exploratory and exploitative activities. A focus on one of these tasks may be easy but combining and balancing them poses a major challenge. Addressing the question of how this dilemma could be solved, this study contributes to the emerging literature of ambidextrous designs and investigates them through the lens of a marketing perspective. The discussion of four different types of ambidexterity has illustrated an increasing number of studies that deals with structural, contextual, and punctuated ambidexterity. In addition, we have introduced a fourth type of peripatric ambidexterity that has so far not been dealt with in the literature. While there has recently been an increasing interest into the issue of ambidexterity, insights into how ambidextrous designs can be implemented in order to solve marketing dilemmas are largely lacking. In addition to specific findings from each of our case firms, several commonalities have emerged that extend the previous literature on ambidexterity.

In the case of structural ambidexterity, the decision to coordinate different activities across organizational units has been identified as an important step (O’Reilly and Tushman 2005). For Deutsche Bank this was an essential move forward to develop a new business approach outside the confines of corporate hierarchies. This solution has also been suggested when executives apply paradoxical cognitions (Smith and Tushman 2005) to frame exploration vs. exploration tensions, e.g. traditional values vs. excitement in banking, and consequently actions in the firm. However, separating units is only one side of the coin and successfully managing an explorative or exploitative unit does not provide insight into how value generated in this unit can be transferred back to other units or even corporate headquarters. While one of the advantages of structural ambidexterity is that it creates "pragmatic boundaries" (Carlile 2004) which safeguards conflicting activities, our findings suggest that employees working in separate units realize the potential paradox of exploration and exploitation but do not necessarily see them as constraints. For instance, Q110 employees capitalize on their specific status, but integrate and reintegrate values and experiences of the different 
units by regular exchanges and potential career moves. Thus, while structural ambidexterity was used to kick-start exploratory innovation in banking, contextually ambidextrous individuals were seen as a necessary condition to maintain the specific status of the subsidiary.

Against conventional insight which focuses on the top management as integrators (O'Reilly and Tushman 2004; Smith and Tushman 2005; Lubatkin, Simek, Lin, and Veiga 2006), Deutsche Bank applies a 'nested design'. On the (inter)personal level, it relies on informal knowledge flows and the recruitment of contextually ambidextrous people. While selected mechanisms like senior team integration or cross-functional interfaces have been discussed, the more informal integration mechanisms should not be underestimated (Jansen, Tempelaar, Van den Bosch, and Volberda 2009). In addition to formal and often pre-established integration mechanisms, informal procedures refer to emergent social properties that influence the way employees exchange knowledge across boundaries (Tsai 2002). In the case of Deutsche Bank, both formal and informal communication channels complement each other, information barriers between units are low, and knowledge exchange is driven by individuals.

In comparing structural and contextual ambidexterity, the former allocates conflicting tasks to different units, but misses the value creating component if subsequent integration is not sufficiently ensured. Hence, the interplay between structural and contextual ambidexterity provided a basic means to support knowledge transfer from exploratory to exploitative units. People with the ability to behave differently in the same context (i.e. contextually ambidextrous managers) or those who are able to switch contexts (which may drive the shift of whole teams towards explorative or exploitative functions, i.e. punctuated ambidexterity) can be seen as vital agents of balancing conflicting marketing strategies. For these capabilities and their efficient allocation across the boundaries of structurally separated units, the organization needs to provide career incentives to support contextually sensitive managers. This leads to continuously creating new combinations of exploratory and exploitative marketing strategies at other levels of the firm (Sirmon, Hitt, and Ireland 2007). This is what both Deutsche Bank and also Celltech did. In promoting former Q110 employees into higher management positions they transferred a creative customer and marketing focus into more exploitation-oriented units. In the case of Celltech, diluting exploitative constraints and progressing to exploration was also based on career options and diversified recruiting.

In the case of Apple, more formal communication structures dominate. What is communicated largely ties to the vision which drives the overall marketing approach, and has spill-over effects to structures and leadership principles. Most implementation parameters are tied to the dominant orientation and implementation success becomes a matter of both communication quality and quantity. For instance, Apple deliberately minimizes communication flows between hardware and software developers (structural separation) and strategic communication channels are dominated from the top. This is equally manifested in the external non-disclose policy as well as limited interdepartmental communication. While it is important that visions are communicated to rationalize both exploratory and exploitative innovation (Jansen, Van den Bosch, and Volberda 2006), in the peripatric version of ambidexterity, one type of strategy at a specific time is emphasized. In order to implement explorative marketing strategies the dominant vision is also reflected in recruiting practices. These focus on intrinsically motivated people who share the approach and are 'fanatics' by themselves. While other ambidextrous designs may fail in this constellation, here the dominance of a top innovator and explorer provides the glue that welds everything together.

This is in stark contrast to contextual ambidexterity (Deloitte Consulting), which integrates an openness of mind into value systems and promotes flexibility in deriving at customer-centric work with high satisfaction rates. While value systems are inspiring, the continuity of the business requires that strategy is flexibly adapted (even though this is unlikely to occur in the form of dramatic jumps). In turn, it requires managerial mindsets that are equally open to conflicting options of exploration and exploitation, especially when acting in an international context. Recent insights in this typical international marketing dilemma have been discussed with reference to the notion of strategic ambidexterity. This captures the trade-off between a multiple pro-growth vs. a focused pro-profit strategy (Han 2007) where the former favours multinational marketing and the latter standardized market operations.

In comparing contextual and punctuated ambidexterity from a knowledge development and recruiting 
perspective, several insights emerge. Both can be explained with reference to the dynamic capability view (Teece, Pisano, and Shuen 1997) which has recently been extended to include marketing dynamic capabilities (MDCs), i.e. "the responsiveness and efficiency of cross-functional business processes for creating and delivering customer value in response to market changes" (Fang and Zou 2009: 3). MDCs are required because the ability to create and deliver superior customer value through efficient and fastresponding marketing processes has become one of the major sources of competitive advantage to firms (Day 1994). It is the customer focus which makes MDCs particularly relevant for this research as it distinguishes MDCs from other dynamic capabilities. In the case of Deloitte, MDCs are specifically related to customer relationship building via trust and capability development which focuses on multicontext and multi-client adaptability. This is in line with what Bartlett and Ghoshal's (1989) focus on integrating recruitment and selection, training and career path management as ways of stimulating a company to become globally integrated and locally responsive at the same time. In contrast, Celltech's capability development is rather product-based (drug development) and process-based (learning to collaborate) where expert competences need to be translated into core technologies and cutting edge offerings.

The differences between variations of ambidexterity is also reflected in the recruiting approaches, which focus either on generalist and client-compatible attitudes (contextual ambidexterity) or in-depth specialist knowledge (punctuated ambidexterity) or on both to be allocated to different units (structural ambidexterity). A specialist focus is required when firms transgress through certain stages, and specialist knowledge provides psychological safety ( $\mathrm{Ne}^{-}$ manich and Vera 2009). However, both the Celltech case and the literature suggest that strategy implementation is improved through flexibly inserting new and disconnected knowledge into the firm which challenge the existing resource base (Guettel and Konlechner 2009). This is especially important when firms experience core technology changes which require the speedy acquisition of new knowledge without rendering previous expert knowledge superfluous. Here, complementing specialists' knowledge by ongoing learning routines which adjust the corporate knowledge base has proved useful. In comparison, peripatric ambidexterity is likely to rely on specialist knowledge to promote and implement one type of strategy without engaging employees into too many cognitive paradoxes (Smith and Tushman 2005). This is not to say that learning does not play a role in a peripatric orientation, but companies need the brightest technological people and often leave soft-skills development to individual initiatives.

In summary, both within and across-case discussions have highlighted different implementation instruments which can be applied to solve marketing dilemmas. These insights may be used for formulating further challenges for research.

\section{Implications for Further Re- search and Marketing Practice}

Implications for further research can be derived from both the limitations and the contributions of this study. The limitations of this research can be divided into three categories. First, in exploratory research small numbers of cases are acceptable, but investigating additional and more varied cases is likely to yield promising insights. Second, with the choice of Apple and Celltech, we presented two examples focused on (the move towards) explorative strategy while insights into the opposite direction would also be useful. Third, in investigating implementation categories, we relied on a mix of existing categories from the marketing strategy and ambidexterity literature. However, both streams of research have not yet reached a stage of consolidated insights which is evidenced by the heterogeneity of approaches and elements (Li, Guohui, and Eppler 2008). One of the immediate consequences in this research relates to initially low inter-rater reliability percentages due to overlapping categories. Thus, further research may start from redefining categories based on empirical insights.

Our results demonstrate that knowledge of ambidextrous designs, associated tools and procedures is a prominent requirement when companies want to solve their marketing dilemmas. Each of the four ambidextrous designs facilitates the solution of different marketing dilemmas and requires a different, partly overlapping, set of implementation factors. These relate both to the personal and the organizational level and warrant further attention (Table 2). Further, studies should not only investigate the implementation of one of the four types of ambidexterity in isolation but focus on their dynamic interplay both within organizations and over time. 
Table 2: Summary and Research Implications

\begin{tabular}{|c|c|c|c|}
\hline & $\begin{array}{l}\text { Marketing Driver of Ambi- } \\
\text { dexterity }\end{array}$ & $\begin{array}{l}\text { Implementation } \\
\text { Personal Level }\end{array}$ & $\begin{array}{l}\text { Implementation } \\
\text { Organizational Level }\end{array}$ \\
\hline Structural ambidexterity & $\begin{array}{l}\text { - New business approach out- } \\
\text { side stagnating core busi- } \\
\text { ness } \\
\text { - Conflicting values of mar- } \\
\text { keting message (e.g. excite- } \\
\text { ment vs. tradition) }\end{array}$ & $\begin{array}{l}\text { - Integration through infor- } \\
\text { mal knowledge flows } \\
\text { - Recruiting of contextually } \\
\text { ambidextrous people }\end{array}$ & $\begin{array}{l}\text { - Transversal careers across } \\
\text { units } \\
\text { - Top management provides } \\
\text { vision and goals but grants } \\
\text { autonomy in procedures }\end{array}$ \\
\hline Peripatric ambidexterity & $\begin{array}{l}\text { - Personality-driven product } \\
\text { and marketing approach } \\
\text { - Desired spill-over effects } \\
\text { (person - organization - } \\
\text { brand) }\end{array}$ & $\begin{array}{l}\text { - Recruiting focus explora- } \\
\text { tion-oriented people } \\
\text { - Intrinsic motivation drivers }\end{array}$ & $\begin{array}{l}\text { - Clear guidelines on work } \\
\text { procedures } \\
\text { - Limited cross-functional } \\
\text { interfaces (in critical areas) }\end{array}$ \\
\hline Contextual ambidexterity & $\begin{array}{l}\text { - Market approach } \\
\text { - Marketing dynamic capa- } \\
\text { bilities }\end{array}$ & $\begin{array}{l}\text { - High motivated to learn and } \\
\text { quickly adjust to new con- } \\
\text { tingencies } \\
\text { - Trust as essential personal } \\
\text { and interpersonal compe- } \\
\text { tence }\end{array}$ & $\begin{array}{l}\text { - Career development with } \\
\text { leeway for technical and } \\
\text { managerial careers } \\
\text { - Managerial support } \\
\text { throughout business proc- } \\
\text { esses, task assignments, ca- } \\
\text { reer perspective }\end{array}$ \\
\hline $\begin{array}{l}\text { Punctuated } \\
\text { ambidexterity }\end{array}$ & $\begin{array}{l}\text { - Core technology changes } \\
\text { (product substitutions) } \\
\text { - Core competence-based } \\
\text { marketing }\end{array}$ & $\begin{array}{l}\text { - Expert knowledge } \\
\text { - Willingness to engage in } \\
\text { learning and knowledge } \\
\text { sharing in addition to ex- } \\
\text { pert status }\end{array}$ & $\begin{array}{l}\text { - Effective linkages between } \\
\text { teams through shared cul- } \\
\text { ture } \\
\text { - Multi-functional project or- } \\
\text { ganization }\end{array}$ \\
\hline
\end{tabular}

In addition, attention should also be paid to situations when firms adopt temporal models of ambidexterity as they are required to optimize the fit between internal design parameters and constantly changing external contingencies. Research may be further inspired by configuration theories (Miller and Friesen 1984) which discuss the interplay between these two types of parameters. It would also be particularly important to analyze whether the use of different types of ambidexterity is conducive to explaining underlying differences in terms of performance.

For marketing practitioners, an understanding of the four types of ambidexterity and the associated implementation tools provides a basis for finding systematic solutions to several common marketing dilemmas. This could imply the tension between marketing established or conventional products and emerging new products which may be resolved by structural ambidexterity. Conflicts between a zealous business development and a sluggish R\&D may point towards the need for a better synchronisation through punctuated ambidexterity. In contrast, if senior management finds its company too research driven but lacking in commercialisation, a new marketing director may offer a solution, i.e., peripatric ambidexterity might be called for. Finally, senior marketing managers will have to give their brand managers sufficient latitude to strike the fine balance between the introduction of new products and the extension of existing products. Thus, creating the right environment for contextual ambidexterity would be the order of the day.

However, as this study has illustrated, rather than focusing on isolated marketing dilemmas, managers will most likely require a more integrated approach. Thus, meeting the multi-layered challenges of successful marketing, they are likely to implement different types of ambidexterity in the firm. Fulfilling singular requirements may be relatively easy and previous research has extensively dealt with the dualism of exploration and exploitation strategies, but as Raisch (2008: 484) urges us "further insights are needed about the specific contexts [of ambidextrous designs], which factors contribute to their successful implementation, and what outcomes are likely to result from their use." This implies that understanding the compatibility of implementation instruments becomes a vital part in pursuing balanced marketing strategies. 


\section{Conclusions}

This study is among the first that adopts a marketing lens to investigating ambidexterity. We contribute to both previous research and managerial practice as to how firms in general - and marketing management in particular - may manage and organize the dual pursuit of exploratory and exploitative strategies. Even though a few existing studies have investigated selected types of ambidexterity, we are currently unaware of any research that includes the notion of peripatric ambidexterity and further discusses the interplay of four different balancing mechanisms. Our findings illustrate that firms use these mechanisms by drawing on a variety of implementation elements. In changing or extending their marketing orientation, managers need to be well aware of the complementary and potentially conflicting use of implementation designs.

\section{Appendix - Details of Methodological Approach}

Each of the four firms, Celltech, Apple, Deloitte, and Deutsche Bank, was approached to provide additional data on the specific ambidexterity type it scored most prominently in the first round, i.e., Deutsche Bank for structural ambidexterity, Deloitte for contextual ambidexterity, Apple for peripatric ambidexterity, and Celltech for punctuated ambidexterity. However, during interviews, new evidence for different types of ambidexterity was found, which gave rise to further analysis.

When (re)contacting these firms and respective interview partners, we encountered a differential willingness to answer further detailed questions. While interviews with Deutsche Bank and Deloitte were continued with semi-structured questionnaires, both Celltech and Apple required a change in the interview approach. Celltech is a company, which was acquired by UCB in 2004 and no longer exists in its original form. In the first round, interviews involved broader aspects of innovation and strategy; but the focus of this second round-investigation relates to very specific developments in the past, and suitable interview partners that experienced Celltech's strategy changes were difficult to find. However, we decided to maintain the firm as it is one of the typical classic cases of punctuated ambidexterity (equilibrium), which is well documented in the case literature (e.g. McNamara and Baden-Fuller 1999; McNamara, Baden-Fuller, and Howell 1999). Con- sequently, our analysis of Celltech is literaturebased and complemented by a few selected interview insights. In the case of Apple we encountered further challenges, which we did not fully realize in the first round. Due to a corporate non-disclosure policy it was difficult to obtain more fine-tuned information. We, therefore, included external partners and former employees. In addition, we used projective techniques in the interview process. Projective or third person techniques are used when the required information cannot be accurately obtained by direct methods (or directly concerned interview partners). They are also highly recommended in exploratory research to provide significant insights (Webb 1992). As qualitative analysis and interpretation of projective techniques are no different from the procedures for qualitative research in general, we continue the analysis phase in the same way as for direct interviewing.

In sum, in the second round we conducted 20 interviews, by applying three complementary methods: traditional interviews based on semi-structured questionnaires, literature-based case analysis, and interviews based on projective techniques. All interviews lasted, on average 90 minutes. When contacting interview partners, all participants were informed that the study was primarily about balancing difficult marketing-related tasks and conflicts, and how to communicate and market these challenges both internally and externally. The term "ambidexterity" was not mentioned initially as previous experience indicates that the majority of managers has not yet encountered the notion of ambidexterity even though most managers use what the literature has identified as 'ambidextrous coordination designs'. This discrepancy is a pertinent issue as managers often use different words than researchers and a shared meaning is required before advancing with the issue (Astley and Zammuto 1992).

In addition to interview data, available material both from the public press, company reports and existing previous research was included for data triangulation (Jick 1979). Resulting insights illustrate our theoretical perspective and describe the challenges associated with implementing each type of ambidexterity. In order to prepare data for analysis, interviews were audio-taped, transcribed and, when necessary, translated into English. Full transcripts of interviews were prepared and, subsequently, abridged to capture the data directly relevant to our research topic. We assigned code numbers to each 
interview per firm (A1, A2, etc. for Apple, B1, B2 etc. for Deutsche Bank, $\mathrm{C} 1, \mathrm{C} 2$, etc. for Celltech, and D1, D2, etc. for Deloitte), which later facilitated the identification of interview quotes and multiple mentions. In the categorization process, nine major categories emerged. Assigning categories was based on a deductive-inductive procedure which combines the advantages of reliability (with criteria derived from theory) and those of validity (which suggest an inductive development that captures the essence of the phenomenon) (Druckman and Hopmann 2002). We started with categories from the implementation literature and complemented them with those mentioned for ambidextrous strategies. We decided to define main categories (9) and maintained sub-categories (24) whenever this seemed useful to support subsequent coding (Srnka and Koeszegi 2007). In the coding process, we assigned interview statements to categories. Statements or "sense units" (Bubert, Gadner, and Richards 2004) have been identified as the best basis for coding and analysis. We independently categorized the 127 statements, which we identified in the interviews, into the nine categories illustrated in the strategy and ambidexterity implementation literature (see Table A.1 for an example of the coding process).

\section{Table A.1: Coding Example}

\begin{tabular}{|c|c|}
\hline Definition - Main Category & $\begin{array}{l}\text { Coding: Firm/Interview No.-Category-Subcategory: Sense unit } \\
\text { with key words in italics }\end{array}$ \\
\hline $\begin{array}{l}\text { Goals: current and future objectives (financial and strategic) of } \\
\text { the firm, both corporate and business unit level; vision of the } \\
\text { firm, vision of CEO, firm development }\end{array}$ & $\begin{array}{l}\text { A3-G(oals)-St(rategic Vision): Sense unit: "[...] and when you are } \\
\text { asked to judge on the future; what you can always say is that there } \\
\text { will be something new, there is constant innovation,... the firm is } \\
\text { constantly re-inventing itself and this is how it defines its strategy." }\end{array}$ \\
\hline $\begin{array}{l}\text { Organizational Context: formal guidelines, controls, monitor- } \\
\text { ing, daily work context that affects motivation, organization of } \\
\text { work environment }\end{array}$ & $\begin{array}{l}\text { B3-O(rganizational)Context-Au(tonomy): Sense unit: "You know, } \\
\text { there are constraining and supporting factors but we work here be- } \\
\text { cause we like the context; we organize our work largely by ourselves, } \\
\text {.. Sense unit: we kind of create our own environment so that eve- } \\
\text { rybody can work according to the best of his abilities and for the } \\
\text { maximum benefit of Q110..." }\end{array}$ \\
\hline
\end{tabular}

As one of the criteria for "good" science is based inter-subjectivity through multiple person involvement, we independently engaged two people in the process of allocating statements to the nine major categories identified in the literature. The researchers initially achieved an agreement of $65 \%$ which is not very high. Major differences occurred in the categories leadership style vs. communications and behavior complexity vs. recrui- ting. Referring back to the strategy implementation literature did, indeed, provide evidence that these categories have often been diluted (Li, Guohui, and Eppler 2008). After in-depth discussion, we increased agreement and were able to allocate all statements to nine categories. The resulting categories and subcategories are summarized in Table A.2 which also depicts the number of mentions per category and some illustrative quotes.

\section{Table A.2: Implementation Categories, Subcategories, and Interview Examples}

\begin{tabular}{|c|c|c|c|}
\hline $\begin{array}{l}\text { Implementation } \\
\text { Categories (num- } \\
\text { ber of mentions) }\end{array}$ & $\begin{array}{l}\text { Litera- } \\
\text { ture Re- } \\
\text { ferences }\end{array}$ & Subcategories & Illustrations \\
\hline $\begin{array}{l}\text { Goals } \\
\text { (11x) }\end{array}$ & $\begin{array}{l}\text { Noble } \\
\text { (1999) }\end{array}$ & $\begin{array}{ll}\text { - } & \text { Corporate } \\
\text { goals } \\
\text { - } \\
\text { - Unit goals } \\
\text { Strategic } \\
\text { vision }\end{array}$ & $\begin{array}{l}\text { A4: "There is always the run after the next hype, you feel the drive and you } \\
\text { know what, when Steve was away, it was different" } \\
\text { B2: "The concept [Q110] was established with a long-term perspective in } \\
\text { mind, but of course it is subject to change. This is pretty clear when we want } \\
\text { to fill the notion 'bank of the future' with life...what is important is new client } \\
\text { generation and we have roughly 50\% higher rates than other subsidiaries; } \\
\text { our client focus in clearly king“" } \\
\text { Clit: "It came from the top. Of course, there were managers further down } \\
\text { but the way we were going to organize ourselves came from David Bloxham } \\
\text { (Director of Research)"; (McNamara et al. 1999: 7) }\end{array}$ \\
\hline
\end{tabular}


Table A.2 continued: Implementation Categories, Subcategories, and Interview Examples

\begin{tabular}{llll}
$\begin{array}{l}\text { Implementation } \\
\begin{array}{l}\text { Categories (num- } \\
\text { ber of mentions) }\end{array}\end{array}$ & $\begin{array}{l}\text { Litera- } \\
\text { ture Re- } \\
\text { ferences }\end{array}$ & Subcategories & Illustrations \\
& & \\
\hline
\end{tabular}

\begin{tabular}{|c|c|c|c|}
\hline & & & $\begin{array}{l}\text { D2: "We always have very clear and challenging objective and we keep them } \\
\text { high... but , actually our strategy is not changing dramatically but the envi- } \\
\text { ronment is and we need to update our knowledge" }\end{array}$ \\
\hline $\begin{array}{l}\text { Structures } \\
(12 \mathrm{x})\end{array}$ & $\begin{array}{l}\text { Govinda- } \\
\text { rajan } \\
\text { (1988) } \\
\text { Drazin and } \\
\text { Howard } \\
\text { (1984) }\end{array}$ & $\begin{array}{ll}\text { - } & \text { Organization } \\
\text { structures } \\
\text { - } & \text { Team struc- } \\
\text { ture } \\
\text { - Integration }\end{array}$ & $\begin{array}{l}\text { A1: "We have several clearly defined structural devices, e.g. international } \\
\text { sales and all the financial functions are coordinated in Cork... but even here, } \\
\text { there are regional structures, even though with few hierarchies... and very } \\
\text { quickly you are in the US" } \\
\text { B8: "We have two teams which deal with customers in a different way. First, } \\
\text { there is the Forum Team, which is the first contact for everybody. These } \\
\text { people are moving freely in the area. Then, we have the Client Team, which } \\
\text { is responsible for fixed meetings, and for coordination subsequent meet- } \\
\text { ings." } \\
\text { C2: "It was very fluid...you were in contact with almost everybody...in the } \\
\text { old times, you went to work and you had your three colleagues, that was it.." } \\
\text { D1: "Of course we have clear structures, but it depends on the level, and it is } \\
\text { more that you facilitate exchange than imposing constraints." }\end{array}$ \\
\hline $\begin{array}{l}\text { Leadership Style } \\
(14 \mathrm{x})\end{array}$ & $\begin{array}{l}\text { Gupta and } \\
\text { Govinda- } \\
\text { rajan } \\
(1984)\end{array}$ & $\begin{array}{l}\text { - } \text { Support } \\
\text { - } \text { Motivation } \\
\text { - Empathy }\end{array}$ & $\begin{array}{l}\text { A4: "He clearly is the great motivator...when you listen to his public } \\
\text { speeches, and even more, when you meet him internally, the vision is alive, it } \\
\text { lives, and he is by no means a normal boss" } \\
\text { A4: "It is crazy how one person drives this firm...you are always expecting } \\
\text { him to introduce the next hype and you discuss it in your team with your } \\
\text { colleagues and you also think about new ideas" } \\
\text { B7: "You know, we all work here because we wanted to; if we work long } \\
\text { hours, this does not really matter because we are motivated, we believe we } \\
\text { are doing an exciting job here, and what's most important...we like it" } \\
\text { Clit: "New management entered the firm but was cautious at first, galvaniz- } \\
\text { ing the commitment of a key group of scientists and administrators prior to } \\
\text { announce a change in strategy" (McNamara and Baden-Fuller, 1999: 304) } \\
\text { D4: "I always try to see the potential of people, I listen intensively, challenge } \\
\text { them... help them, and discuss options with them" }\end{array}$ \\
\hline $\begin{array}{l}\text { Communications } \\
(21 \mathrm{x})\end{array}$ & $\begin{array}{l}\text { Westley } \\
(1990) \\
\text { Rapert, } \\
\text { Velliquet- } \\
\text { te, and } \\
\text { Garretson } \\
\text { (2002) }\end{array}$ & $\begin{array}{ll}\text { - } & \text { Informal } \\
\text { communica- } \\
\text { tion } \\
\text { - Formal } \\
\text { communica- } \\
\text { tion }\end{array}$ & $\begin{array}{l}\text { A2: "You get to know what is important for your work but sometimes I } \\
\text { would like to be more involved. Also, you hear different things from different } \\
\text { people as if they do not communicate with each other" } \\
\text { B8: „It is important that you do not only focus on your own things but also } \\
\text { show responsibility towards each other and act to support the customer best. } \\
\text { This requires that you, kind of anticipate what others will do but also that } \\
\text { you constantly communicate“ } \\
\text { C1:"There were so many diverse opinions, people looked at the world differ- } \\
\text { ently...we were constantly in the process of negotiation, you know this was } \\
\text { everywhere, we did not rely on any official communications channels...but of } \\
\text { course, there was also information coming from the boss" } \\
\text { D4: "Much is based on trust. I try to communicate clearly and build a rela- } \\
\text { tionship. It is like with external clients. Once they work with you they know } \\
\text { they can trust us and we help them. It is sometimes that these relationships } \\
\text { are more important than the knowledge because others also have this } \\
\text { knowledge” }\end{array}$ \\
\hline $\begin{array}{l}\text { Incentives } \\
(9 x)\end{array}$ & $\begin{array}{l}\text { Walker, } \\
\text { Churchill, } \\
\text { and Ford } \\
(1977)\end{array}$ & $\begin{array}{ll}\text { - } & \text { Financial } \\
\text { - Immaterial }\end{array}$ & $\begin{array}{l}\text { A1: "Formal financial incentives are very rare...this was different earlier, but } \\
\text { today, you have to launch a big bang. But you work in this company and } \\
\text { quite often you feel this is an incentive..." } \\
\text { B3: "There is no differences in financial rewards, this is pretty much the } \\
\text { same across all subsidiaries.. B3: “...many people, after they left Q11o have } \\
\text { continued their management career somewhere else within Deutsche Bank. } \\
\text { Having worked for Q110 is apparently seen as a preparation for major career } \\
\text { jumps" }\end{array}$ \\
\hline
\end{tabular}


Table A.2 continued: Implementation Categories, Subcategories, and Interview Examples

$\begin{array}{llll}\begin{array}{l}\text { Implementation } \\ \text { Categories (num- } \\ \text { ber of mentions) }\end{array} & \begin{array}{l}\text { Litera- } \\ \text { ture Re- } \\ \text { ferences }\end{array} & \text { Subcategories } & \text { Illustrations } \\ \end{array}$

C2: "We had very formal appraisal systems and there was an additional incentive system with quarterly bonus awards for exceptional contributions." D2: "You can imagine that incentives are attractive and we expect a lot. In the long run, it will be your overall performance that brings you to partner level and, apart from everything else, this is well rewarded"

$\begin{array}{ll}\text { Culture } & \begin{array}{l}\text { Nemanich } \\ \text { and Vera } \\ (2009)\end{array} \\ (16 x) & \text { Team spirit }\end{array}$

A5: "You find many people here late in the night who discuss and experiment with colleagues...it is there that you develop the best ideas"

B1: "We have a strong team spirit and we help each other even if this is sometimes difficult ... especially if you look at the large area here. But it is clear that we try to permanently be in touch, this also relates to communications between teams and between bankers and shop employees and - you know, even though the latter are not bankers, they are employed by DB, we have no typical shop in the shop principle here"

Clit: "We created a culture of flexibility. For instance, one principle is the sanctioning of scientists spending up to 10 percent of their time on individual projects...We want them the use their knowledge in a direction unconstrained by project requirements" (McNamara, Baden-Fuller, and Howell 1999: 12)

D3: "We have a very open culture, where we are critical and challenge each other. We are interested in what people and their potential to contribute, and this is what we permanently encourage"

\begin{tabular}{llll}
\hline $\begin{array}{l}\text { Organizational } \\
\text { Context }\end{array}$ & $\begin{array}{l}\text { Bartlett } \\
\text { and Gho- }\end{array}$ & $\bullet$ Autonomy \\
& shal & Guidelines / \\
(11x) & Control \\
& Jaworski & Managerial \\
& and McIn- & \\
& Support \\
& nis (1989) & \\
&
\end{tabular}

A1: "It's simply that you can do what you like most. People hang around late hours and discuss the newest gadgets, others go early or work from home... you can really influence your own work environment"

A1: "There are very clear and strict guidelines and you normally check with your boss and make sure he agrees"

B2: "Of course, there were guidelines but they used to be much stronger ... Today, there are many things we can largely decide on our own and quite often only briefly check back with the HQ. In fact, is has happened that ideas developed from the HQ did not work at all in our subsidiary"

B4: "People who work here have a good feeling for what works and what it is that customers like"

Clit: 'You manage the projects by objectives and milestones.. You have regular quarterly reviews, after all, we are a small company so you can monitor things reasonably closely”. (McNamara, Baden-Fuller, and Howell 1999: 10). D3: "We have, and need to have financial objectives, which means you should really spend your time on billable hours with the client. But the natural context allows for time to do research, and you are not far away from your clients when you develop something because we listen to clients and involve them in research"

\begin{tabular}{llll}
\hline $\begin{array}{l}\text { Behavioral Com- } \\
\text { plexity }\end{array}$ & $\begin{array}{l}\text { Sproull } \\
\text { and Hof- } \\
\text { meister } \\
(1986)\end{array}$ & ・ & $\begin{array}{l}\text { Role Behav- } \\
\text { ior }\end{array}$ \\
(17x) & Commitment
\end{tabular}

A5: "While people seem to have huge leeway in what they do, I have the feeling that there are serious constraints in how flexibly they can really act" B3" We need to be flexible here, we incorporate different roles, from event manager to conservative banker. We need to adjust to our clients because client satisfaction is key"

B5 "every employee is not only banker but always something like a customer relationship manager, a PR specialist, in short someone who thinks out of the box. You need to sell not only banking service but also kitchen accessories and concert tickets and you need to live this!!"

C1: "It was quite amazing. Formerly, you were a specialist in your field.. you still continued to be one but the new task was to move out of the box and increase interdepartmental knowledge sharing"

D1: "People travel from London to Spain to Portugal, all within one week. They communicate fluently in these languages and shift between cultures. Of course, you also have this in client relations. For some consultants, it is certainly less challenging to spend more time on office work" 
Table A.2 continued: Implementation Categories, Subcategories, and Interview Examples

\begin{tabular}{|c|c|c|c|}
\hline $\begin{array}{l}\text { Implementation } \\
\text { Categories (num- } \\
\text { ber of mentions) }\end{array}$ & $\begin{array}{l}\text { Litera- } \\
\text { ture Re- } \\
\text { ferences }\end{array}$ & Subcategories & Illustrations \\
\hline $\begin{array}{l}\text { Recruiting } \\
(16 x)\end{array}$ & $\begin{array}{l}\text { Pearce and } \\
\text { Robinson } \\
(2005)\end{array}$ & $\begin{array}{ll}\text { - } & \text { Personality } \\
\text { - } & \text { Education } \\
\text { - } & \text { Learning } \\
& \text { Skills }\end{array}$ & $\begin{array}{l}\text { A4: "It's not a normal firm, they are all fanatics. Even our bankers are not } \\
\text { normal bankers. You have to be a special type of person here and you need } \\
\text { to like it. Perhaps, this is already a self-selection criterion in the recruitment } \\
\text { process..." } \\
\text { B4: "Criteria for recruiting are fairly simple: openness, a basic interest in the } \\
\text { job, you use of body language. Probably, there is a self-selection process, } \\
\text { people come here because they want to work here, later on they receive } \\
\text { trainings and coaching." } \\
\text { Clit:"...simultaneously, } 35 \text { medical chemists were brought into the firm. } \\
\text { This new blood not only provided key skills needed to implement the new } \\
\text { strategy, but also a group of people who could stimulate and challenge" } \\
\text { (Dodgson, 20o1: 144) } \\
\text { D4: "Individual objectives and career perspectives can change and then we } \\
\text { discuss new options.. and there often is an option to change careers in the } \\
\text { firm, like from managerial aspirations to technical expertise...so we are basi- } \\
\text { cally looking for open-minded people who can communicate well and who } \\
\text { also have the personality to stand in front of the client" }\end{array}$ \\
\hline
\end{tabular}

\section{References}

Adner, Ron and Daniel A. Levinthal (2002): The Emergence of Emerging Technology, California Management Review, 45 (1): 50-66.

Adler, Paul, Barbara Godolftas, and David Levine (1999): Flexibility versus Efficiency? A Case Study of Model Changeovers in the Toyota Production System, Strategic Management Journal, 24: 1011-1025.

Akşin, O. Zeynep and Patrick T. Harker (1999): To Sell or Not to Sell: Determining the Trade-offs Between Service and Sales in Retail Banking Phone Centers, Journal of Service Research, 2: 19-33.

Ambos, Bjoern and Bodo B. Schlegelmilch (2005): In Search of Global Advantage, European Business Forum, 21: 23-24.

Astley, W. Graham and Raymond F. Zammuto (1992): Organization Science, Managers, and Language Games, Organization Science, 3: 443-460.

Auh, Seigyoung and Bulent Menguc (2005): Balancing Exploration and Exploitation: The Moderating Role of Competitive Intensity, Journal of Business Research, 58: 1652-1661.

Bass, Bernard M. (1985): Leadership and Performance Beyond Expectation, Free Press: New York.

Beckman, Christine M. (2006): The Influence of Founding Team Company Affiliations on Firm Behavior, Academy of Management Journal, 49: 741-758.

Birkinshaw, Julian and Cristina Gibson (2004): Building Ambidexterity into an Organization, Sloan Management Review, 45 (4): 47-55.

Benner, Mary J. and Michael L. Tushman (2003): Exploitation, Exploration, and Process Management: The Productivity Dilemma Revisited, Academy of Management Review, 28: 238-256.

Boeker, Warren (1997): Executive Migration and Strategic Change: The Effect of Top Manager Movement on ProductMarket Entry, Administrative Science Quarterly, 42: 213-236.
Bonoma, Thomas V. (1984): Making Your Marketing Strategy Work, Harvard Business Review, 62 (2): 69-76.

Bonoma, Thomas V. and Victoria L. Crittendon (1988): Managing Marketing Implementation, Sloan Management Review, 29 (4): 7-14.

Brown, John S. and Paul Dugoid (1991): Organizational Learning and Communities of Practice: Towards a Unified View of Working, Learning, and Innovation, Organization Science, 2: 40-57.

Brown, Shona L. and Kathleen M. Eisenhardt, (1997): The Art of Continuous Change: Linking Complexity Theory and TimePaced Evolution in Relentlessly Shifting Organizations, Administrative Science Quarterly, 42: 1-34.

Bubert, Renate, Johannes Gadner, and Lyn Richards (2004): Applying Qualitative Methods to Marketing Management Research, Palgrave McMillan: Houndsmill et al.

Burgelman, Richard A. (2002): Strategy as a Vector and the Inertia of Co-evolutionary Lock-in, Administrative Science Quarterly: 47: 325-358.

Burns, James (1978): Leadership, Harper \&Row: New York.

Burns, Tom and George M. Stalker (1961): The Management of Innovation, Tavistock: London.

Carlile, Paul R. (2004): Transferring, Translating and Transforming: An Integrated Framework for Managing Knowledge Across Boundaries, Organization Science, 15: 555-568.

Carmeli, Abraham and Meyrav Y. Halevi (2009): How Top Management Teams Behavioral Integration and Behavioral Complexity enable Organizational Ambidexterity. The Moderating Role of Contextual Ambidexteritxy, The Leadership Quarterly, 20: 207-218.

Carson, Stephen (2007): When to Give Up Control of Outsourced New Product Development, Journal of Marketing, 71 (1): 49-66.

Chimhanzi, Jaqueline and Robert E. Morgan (2005): Explanations from the Marketing/Human Resource Dyad for Market- 
ing Strategy Implementation Effectiveness in Service Firms, Journal of Business Research, 58: 87-796.

Cespedes, Frank (1991): Organizing and Implementing the Marketing Effort, Addison-Wesley: Reading, Mass.

Christensen, Clayton M. and Michael Raynor (2003): The Innovator's Solution, Harvard Business School Press: Boston.

Churchill, Gilbert A. and Dawn Iacobcci (2005): Marketing Research: Methodological Foundations, $9^{\text {th }}$ Edition, Thompson South-Western: Mason, Ohio.

Danneels, Erwin (2002): The Dynamics of Product Innovation and Firm Competencies, Strategic Management Journal, 23: 1095-116.

Day, George S. (1994): The Capabilities of Market-Driven Organizations, Journal of Marketing, 58 (2): 37-52.

Day, George S. (1989): Deciding How to Compete, Planning Review, 17 (5): 18-23.

Deming, W.E. (1981): Management of Statistical Techniques for Quality and Productivity, New York University Graduate School of Business: New York.

Dobni, C. Brooke (2006): Developing an Innovation Orientation in Financial Services Organizations, Journal of Financial Services Marketing, 11: 166-179.

Dodgson, Mark (1991): Technology Learning, Technology Strategy and Competitive Pressures, British Journal of Management, 2: 133-149.

Drazin, Robert and Peter Howard (1984): Strategy Implementation: A Technique for Organizational Design, Columbia Journal of World Business, 19: 40-46.

Druckman, Daniel and Terrance Hopmann (2002): Content Analysis, in: Kremenyuk, V.A. (ed.), International Negotiation: Analysis, Approaches, Issues, Jossey-Bass: San Francisco, 288314.

Duncan, Robert B. (1976): The Ambidextrous Organization: Designing Dual Structures for Innovation, in: Pondy, Lois R. and Dennis P. Slevin (eds.): The Management of Organization Design: Volume, Strategies and Implementation, Elsevier: New York, 167-188.

Evans, Kenneth R., Todd J. Arnold, and John A. Grant (1999), Combining Service and Sales at the Point of Customer Contact: A Retail Banking Example, Journal of Service Research, 2 (1): 3449.

Fang, Eric and Shaoming Zou (2009): Antecedents and Consequences of Marketing Dynamic Capabilities in International Joint Ventures, Journal of International Business Studies, 40: 742761.

Fiedler, Fred (1967): A Theory of Leadership Effectiveness, McGraw-Hill: New York.

Floyd, Steven and Peter W. Lane (2000): Strategizing throughout the Organization: Managing Role Conflict in Strategic Renewal, Academy of Management Review, 25: 154-177.

Forman, Janis and Paul A. Argenti (2005), How Corporate Communication Influences Strategy Implementation, Reputation and the Corporate Brand: An Exploratory Qualitative Study, Corporate Reputation Review, 8: 245-264.

Franckwick, Gary, James C. Ward, Michael D. Hutt, and Peter Reingen (1994): Evolving Patterns of Organizational Belief in the Formation of Strategy, Journal of Marketing, 58 (2): 96-110.

Gale, Bradley (1992): Monitoring Customer Satisfaction and Market-perceived Quality, American Marketing Association Worth Repeating Series, Number $022 \mathrm{CSO} 1$.

Gersick, Connie (1991): Revolutionary Change Theories: A Multilevel Exploration of the Punctuated Equilibrium Paradigm, Academy of Management Review, 16: 10-36.

Ghoshal Sumantra and Christopher A. Bartlett (1994): Linking Organizational Context and Managerial Action: The Dimensions of Quality of Management, Strategic Management Journal, 15: 91-112.

Gibson, Cristina and Julian Birkinshaw (2004): The Antecedents, Consequences, and Mediating Role of Organizational Ambidexterity, Academy of Management Journal, 47: 209-226.

Govindarajan, Vijay. (1988): A Contingency Approach to Strategy Implementation at the Business Unit Level: Integrating Administrative Mechanisms with Strategy, Academy of Management Journal, 27: 25-41.

Greve, Heinrich R. (2007): Exploration and Exploitation in Product Innovation, Industrial and Corporate Change, 16: 945975.

Griffin, Abbie and John H. Hauser (1996): Integrating R\&D and Marketing: A Review and Analysis of the Literature, Journal of Product Innovation Management, 13: 191-215.

Güttel, Wolfgang H. and Stefan W. Konlechner (2009): Continuously Hanging by a Thread: Managing Contextually Ambidextrous Organizations, Schmalenbach Business Review, 61: 149171.

Gupta, Anil K., Ken G. Smith, and Christina E. Shalley (2006): The Interplay Between Exploration and Exploitation, Academy of Management Journal, 49: 693-706.

Han, Mary (2007): Achieving Superior Internationalization Through Strategic Ambidexterity, Journal of Enterprising Culture, 15: 43-77.

Hart, Stuart and Catherine Banbury (1994): How StrategyMaking Processes Can Make a Difference, Strategic Management Journal, 15: 251-268.

He Zi-Lin and Poh-Kam Wong (2004): Exploration versus Exploitation: An Empirical Test of the Ambidexterity Hypothesis, Organization Science, 15: 481-494.

Jansen, Justin J. P., Frans A. J. Van den Bosch, and Henk W. Volberda (2005): Exploratory Innovation, Exploitative Innovation, and Ambidexterity: The Impact of Environmental and Organizational Antecedents, Schmalenbach Business Review, 57: 351-363.

Jansen, Justin J. P., Michiel P. Tempelaar, Frans A. J. Van den Bosch, and Henk W. Volberda (2009): Structural Differentiation and Ambidexterity: The Mediating Role of Integration Mechanisms, Organization Science, 20: 797-811.

Jaworski, Bernard and Deborah J. McInnis (1989): Marketing Jobs and Management Control: Towards a Framework, Journal of Marketing Research, 26: 406-19.

Jaworski, Bernard., Ajay K. Kohli, and Arvind Sahay (2000): Market-driven versus driving-markets, Journal of the Academy of Marketing Science, 28: 45-54 
Jick, Todd D. (1979): Mixing Qualitative and Quantitative Methods, Triangulation in Action, Administrative Science Quarterly, 24: 602-611.

Juran Joseph M. and Frank M. Gryna (1988): Juran's Quality Control Handbook, McGraw Hill, Inc.: New York.

Katila Riita and Gautam Ahuja (200o): Something Old, Something New: A Longitudinal Study of Search Behavior and New Product Introductions, Academy of Management Journal, 45: 1183-1194.

Klein, Katherine J., Fred Dansereau, and Rosalie I. Hall (1994): Levels Issues in Theory Development, Data Collection, and Analysis, Academy of Management Review, 19: 195-229.

Kraatz Matthew S. and James H. Moore (2002): Executive Migration and Institutional Change, Academy of Management Journal, 45: 120-143.

Kumar, Nirmalya (1997): The Revolution in Retailing: from Market Driven to Market Driving, Long Range Planning, 30: 830-836.

Kyriakopoulos, Kyriakos and Christine Moorman, C. (2004): Tradeoffs in Marketing Exploitation and Exploration Strategies: The Overlooked Role of Market Orientation, International Journal of Research in Marketing, 21: 219-240.

Lavie Dovev and Lori Rosenkopf (2006): Balancing Exploration and Exploitation in Alliance Formation, Academy of Management Journal, 49: 791-818.

Lee, Jeho and Young U. Ryu (2002): Exploration, Exploitation, and Adaptive Rationality: The Neo-Schumperian Perspective, Simulation Modeling Practice and Theory, 10 (5-7): 297-320.

Leonard-Barton, Dorothy (1992): Core Capabilities and Core Rigidities: A Paradox in Managing New Product Development, Strategic Management Journal, 13 (S1): 111-125.

Lewis, Marianne W. (2000): Exploring Paradox: Toward a More Comprehensive Guide, Academy of Management Review, 25: $760-776$.

Levinthal Daniel A. and James G. March (1993): The Myopia of Learning, Strategic Management Journal, 14: 95-112.

Li , Yang, Sun Guohui, and Martin J. Eppler (2008): Making Strategy Work: A Literature Review on the Factors Influencing Strategy Implementation, ICA Lugano, Working Paper 2/2008: 1-46.

Lubatkin, Michael H., Zeki Simek, Yan Lin, and John F. Veiga (2006): Ambidexterity and Performance in Small-to Medium- Sized Firms: The Pivotal Role of Top Management Team Behavioral Integration, Journal of Management, 32: 646-672.

March, James G. (1991): Exploration and Exploitation in Organizational Learning, Organization Science, 2: 71-87.

Mayr, Ernst (1942): Systematics and the Origin of Species, Columbia University Press: New York.

McDonough Edward F. and Richard Leifer (1983): Using Simultaneous Structures to Cope with Uncertainty, Academy of Management Journal, 26: 727-735.

McEwen, William (2008): The Chief Marketing Officer's Dilemma, Gallup Management Journal, March 13, 2008, http://gmj.gallup.com/content/104704/Chief-MarketingOfficers-Dilemma.aspx (Access Date: 5 April, 2009)
McGrath, Rita G. (2001): Exploratory Learning, Innovative Capacity and Managerial Oversight, Academy of Management Journal, 44: 118-131.

McNamara, Peter and Charles Baden-Fuller, C. (1999): Lessons from the Celltech Case: Balancing Knowledge Exploration and Exploitation in Organizational Renewal, British Journal of Management, 10: 291-307.

McNamara, Peter, Charles Baden-Fuller, and James Howell (1999): The Rejuvenation of Celltech in the199os: Laying the Foundations of a FTSE 100 Company, ECCH Case Study No. 300-072-1.

Menguc, Bulent and Seigyoung Auh (2008): The Asymmetric Moderating Role of Market Orientation on the Ambidexterity - Firm Performance Relationship for Prospectors and Defenders, Industrial Marketing Management, 37: 455-470.

Miles, Matthew, B. and A. Michael Huberman (1984), Qualitative Data Analysis, 2nd ed., Sage Publications: London.

Miller, Danny and Peter H. Friesen (1984): Organizations: A Quantum View, Prentice-Hall, Englewood Cliffs, NJ.

Miller, Danny and Peter H. Friesen (1986): Porter's Generic Strategies and Performance, Organization Studies, 7: 37-56.

Mom, Tom J.M. (2007): Managers' Exploration and Exploitation Activities: The Influence of Organizational Factors and Knowledge Inflows, Dissertation, Erasmus University Rotterdam.

Morris, Betsy (2008): What Makes Apple Golden, Fortune, March 17, 2008, 157 (5): 68-71.

Nemanich, Loise A. and Vera Duysa (2009): Transformational Leadership and Ambidexterity in the Context of an Acquisition, The Leadership Quarterly, 20: 19-33.

Noble, Charles H. (1999): Building the Strategy Implementation Network, Business Horizons, 42 (6): 19-28.

Noble, Charles H. and Michael P. Mokwa (1999): Implementing Marketing Strategies: Developing and Testing a Managerial Strategy, Journal of Marketing, 63 (4): 57-73.

O'Reilly Charles A. and Michael L. Tushman (2004): The Ambidextrous Organization, Harvard Business Review, 82 (4): 74-81.

O’Reilly Charles A. and Michael L. Tushman (2007): Ambidexterity as a Dynamic Capability: Resolving the Innovator's Dilemma, Research Paper No. 1963, Stanford Graduate School of Business.

Osborn, Richard N., James G. Hunt, and Lawrence R. Jauch (2002): Toward a contextual theory of leadership, The Leadership Quarterly, 13: 707-837.

Peirce, John and Richard Robinson (2005): Formulation, Implementation, and Control of Competitive Strategy, New York: McGraw Hill:

Porter, Michael E. (1980): Competitive Strategy, The Free Press: New York.

Porter, Michal E. (1996): What is Strategy?, Harvard Business Review, 74 (6): 61-78.

Puranam, Pranish, Harbir Singh, and Maurizio Zollo (2006): Organizing for Innovation: Managing the Coordination-Autonomy Dilemma in Technology Acquisitions, Academy of Management Journal, 49: 263-280. 
Quelch, John A. (2005): Ambidextrous Marketing, The Wall Street Journal, October 11, B2.

Raisch, Sebastian (2008): Balanced Structures: Designing Organizations for Profitable Growth, Long Range Planning, 41: 483-508.

Raisch, Sebastian and Julian Birkinshaw (2008): Organizational Ambidexterity: Antecedents, Outcomes, and Moderators, Journal of Management, 34: 375-409.

Rapert, Molly I., Anne Velliquette, and Judith A. Garretson (2002): The Strategic Implementation Process Evoking Strategic Consensus through Communication, Journal of Business Research, 55: 301-310.

Roethaermel Frank T. and David L. Deeds (2004): Exploration and Exploitation Alliances in Biotechnology: A System of New Product Development, Strategic Management Journal, 25: 201221

Shashittal, Hemant C. and David Whilemon (1996): Marketing Implementation in Small and Midsized Industrial Firms, Industrial Marketing Management, 25: 67-78.

Schneider, Benjamin and David E. Bowen (1995): Winning the Service Game, Harvard University Press: Boston.

Sculley John and David Byrne (1987): Odyssey: Pepsi to Apple, A Journey of Adventure. Ideas and the Future, Harper Collins: New York, 147.

Siggelkow Nicolai and Daniel A. Levinthal (2003): Temporarily Divide to Conquer: Centralized, Decentralized, and Reintegrated Organizational Approaches to Exploration and Adaptation, Organization Science, 14: 650-669.

Simek, Zeki (2009): Organizational Ambidexterity: Towards a Multilevel Understanding, Journal of Management Studies, 46: 597-624.

Sirmon, David G., Michael Hitt, and R. Duane Ireland (2007): Managing firm-resources in dynamic environments to create value: Looking inside the black box, Academy of Management Review, 32: 273-292.

Smith, Wendy and Michael L. Tushman (2005): Managing Strategic Contradictions: A Top Management Model for Managing Innovation Streams, Organization Science, 16: 522-536.

Souder, William E. and Alok C. Chakrabarti, (1978): The R\&D/Marketing Interface: Results from an Empirical Study on Innovation Projects, IEEE Transaction on Engineering, 25 (4): 88-93.

Sproull, Lee S. and Kay R. Hofmeister (1986): Thinking about Implementation, Journal of Management, 12: 43-60.

Srnka, Katharina J. and Sabine T. Koeszegi (2007): From Words to Numbers: How to Transform Qualitative Data into Meaningful Quantitative Results, Schmalenbach Business Review, 59: 29-57.

Teece, David, Gary Pisano, and Amy Shuen (1997): Dynamic Capabilities and Strategic Management, Strategic Management Journal, 18: 509-533.

Thompson James D. (1967): Organizations in Action: Social Sciences Bases of Administrative Theory, McGraw Hill: New York.

Tsai, Wenpin (2002): Social structure of 'coopetition' within a multiunit organization: Coordination, competition, and intra- organizational knowledge sharing, Organization Science, 13: 179190.

Tushman, Michael L. and Elaine Romanelli (1994): Organizational Transformation as Punctuated Equilibrium: An Empirical Test, Academy of Management Journal, 37: 1141-1166.

Tushman Michael L. and Charles A. O'Reilly (1996): Ambidextrous Organizations: Managing Evolutionary and Revolutionary Change, California Management Review, 38 (4): 8-30.

Tushman Michael L. and Charles A. O'Reilly (1997): Winning Through Innovation: A Practical Guide to Leading Organizational Change and Renewal, Harvard University Press: Boston.

Virany, Beverly, Michael Tushman, and Elaine Romanelli (1992): Executive Succession and Organizational Outcomes in Turbulent Environments: An Organizational Learning Approach, Organization Science, 3: 72-92.

Volberda, Henk W. (1998): Building the Flexible Firm, Oxford University Press: Oxford.

Walker, Orville C. and Robert Rueckert (1987): Marketing's Role in the Implementation of Business Strategy: A Critical Review and Conceptual Framework, Journal of Marketing, 51 (3): $15-33$

Walker, Orville C., Gilbert A. Churchill, and Neil M. Ford (1977): Motivation and Performance in Industrial Selling: Present Knowledge and Needed Research, Journal of Marketing Research, 14: 156-168.

Webb, James (1992): Understanding and Designing Marketing Research, Academic Press: London.

Westley, Frances (1990): Middle Managers and Strategy: Micro-dynamics and Inclusion, Strategic Management Journal, 11: $337-51$.

White, J. Chris, Jeffrey S. Conant, and Raj Echambadi (2003): Marketing Strategy Development Styles, Implementation Capability, and Firm Performance: Investigating the Curvilinear Impact on Multiple Strategy-Making Styles, Marketing Letters, 14: 111-124.

Woolridge, Bill and Steven W. Floyd (1989): Research Notes and Communications: Strategic Process Effects on Consensus, Strategic Management Journal, 10: 295-302.

\section{Biographies}

Christiane Prange, Dipl.-Kffr., Ph.D., is an Associate Professor of International Marketing and Strategy at EM Lyon Business School in France. After several years in industry and management consulting she returned to academia and obtained her Ph.D. from Geneva University. Switzerland. She held both teaching and research positions with the Open University and the University of Liverpool in the UK, the Vienna University of Economics and Business Administration in Austria as well as visiting assignments in several Asian and European countries.

Bodo B. Schlegelmilch, M.Sc., Ph.D., D.Litt., is Dean of the WU Executive Academy and Professor of International Marketing and Management at the Vienna University of Economics and Business Administration (WU) and at Leeds University Business School. He is also a Fellow of the Chartered Institute of Marketing and Adjunct Professor of International Business Studies at the University of Minnesota, Carlson School of Management and at Kingston University, London, UK. 